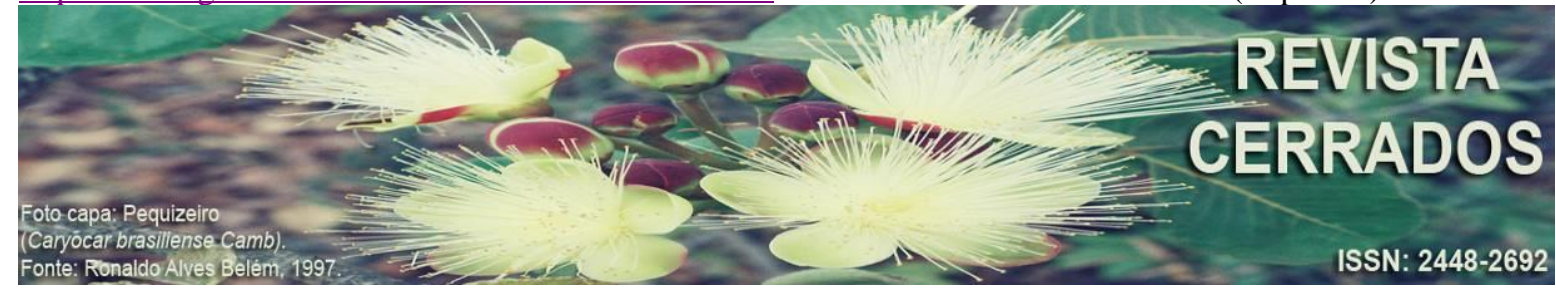

\title{
REFLEXOS DAS OCUPAÇÕES URBANAS NA MOBILIDADE ÀS MARGENS DA RODOVIA ESTADUAL GO-060 ENTRE GOIÂNIA (GO) E TRINDADE (GO)
}

\section{REFLEXES OF URBAN OCCUPATIONS ON MOBILITY TO THE MARGINS OF THE STATE ROAD GO-060 BETWEEN GOIÂNIA (GO) AND TRINDADE (GO)}

\section{REFLETS DES OCCUPATIONS URBAINES SUR LA MOBILITÉ LE LONG DE LA ROUTE D'ÉTAT GO-60 ENTRE GOIANIA (GO) ET TRINDADE (GO)}

\author{
Denis Biolkino de Sousa Pereira (iD \\ Instituto Federal de Educação, Ciência e Tecnologia de Goiás - IFG, \\ Goiânia, Goiás, Brasil \\ E-mail: <denisbiolkino@terra.com.br>. \\ William Rodrigues Ferreira \\ Universidade Federal de Uberlândia - UFU, Uberlândia, \\ Minas Gerais, Brasil \\ E-mail: 〈wferreira@ufu.br>.
}

\section{RESUMO}

O estudo pretende compreender a dinâmica dos diversos tipos de ocupações implantadas no entorno da Rodovia Estadual GO- 060, entre a cidade de Goiânia (GO) e Trindade (GO), e os seus reflexos na mobilidade urbana. O problema se identifica na relação causa e efeito no conflito entre o espaço urbano e o sistema de transportes, em áreas conurbadas da Região Metropolitana de Goiânia (GO). O objetivo consiste em analisar as áreas de ocupação do recorte espacial, o fluxo veicular dos modos de transportes e o índice de mobilidade, em função das tipologias de ocupação, caracterizadas como polos geradores de viagens (PGVs). Para se identificar tais ocorrências, foram utilizadas metodologias adaptadas para análise espaço-temporal e redes. Os resultados mostraram as diferenças em áreas de ocupação nos PGVs Tipo Comércio/Indústria 25,74\% e 30,77\% e Tipo Residencial 11,41\% e 38,78\% para as Regiões Oeste/Mendanha e Trindade 2, para os períodos (2011/2016) e (2009/2015), respectivamente. Essa dinâmica ocupacional gerou um aumento de $+87 \%$ no total de viagens do fluxo dos diversos modos de transporte e um acréscimo de $+79 \%$ no índice de mobilidade 
PEREIRA, D. B. S.; FERREIRA, W. R.

Reflexos das ocupações urbanas na mobilidade às margens da Rodovia Estadual GO-060 entre Goiânia (GO) e Trindade (GO)

para o período de 2013 a 2016, mostrando a tendência de motorização das regiões e os reflexos na mobilidade urbana.

Palavras-chave: Ocupação espacial. Sistema viário. Fluxo veicular. Transporte. Mobilidade.

\begin{abstract}
The study aims to understand the dynamics of the various types of occupations implanted around the State Highway GO-060, between the city of Goiânia (GO) and Trindade (GO), and their reflexes on urban mobility. The problem is identified in the cause and effect relationship in the conflict between urban space and the transport system in conurbated areas of the Metropolitan Region of Goiânia (GO). The objective is to analyze the areas of occupation of the spatial area, the vehicular flow of the modes of transport and the mobility index, according to the types of occupation, characterized as travel generating poles (TGPs). To identify such occurrences, methodologies adapted for spatiotemporal analysis and networks were used. The results showed the differences in occupation areas in the Trade / Industry Type $25.74 \%$ and $30.77 \%$ and Residential Type $11.41 \%$ and $38.78 \%$ for the West / Mendanha and Trindade 2 Regions for the periods (2011/2016) and (2009/2015) respectively. This occupational dynamic generated an increase of $+87 \%$ in the total travel flow of the different modes of transport and an increase of $+79 \%$ in the mobility index for the period from 2013 to 2016, showing the trend of motorization in the regions and the reflexes in urban mobility.
\end{abstract}

Keywords: Spatial occupation. Road system. Vehicular flow. Transport. Mobility.

\title{
RÉSUMÉ
}

L'étude prétend comprendre la dynamique des divers types d'occupations implantées le long de la Route d'État GO-060, entre les villes de Goiânia (GO) et Trindade (GO), et ses retombées sur la mobilité urbaine. Le problème s'identifie dans la relation de cause à effet dans le conflit entre espace urbain et système de transport, dans les aires urbanisées de la Région Métropolitaine de Goiânia (GO). L'objectif est d'analyser les zones d'occupation du découpage spatial, le flux routier des modes de transport et l'indice de mobilité selon les typologies d'occupation, caractérisées comme pôles générateurs de voyages (PGVs). L'identification de ces faits s'est réalisée par l'utilisation de méthodologies adaptées à l'analyse spatio-temporelle et de réseaux. Les résultats montrent des différences de PGVs dans les zones d'occupation du type Commerce/Industrie $25,74 \%$ et $30,77 \%$ et du type résidentiel $11,41 \%$ et $38,78 \%$ pour les régions Ouest/Mendanha et Trindade 2, respectivement pour les périodes $(2011 / 2016)$ et $(2009 / 2015)$. Cette dynamique d'occupation révèle une augmentation de $+87 \%$ du total de voyages de flux des différents modes de transport et une croissance de $+79 \%$ de l'indice de mobilité pour la période de 2013 à 2016, montrant la tendance de motorisation des régions et ses reflets sur la mobilité urbaine.

Mots clés: Occupation spatial. Système routier. Flux de véhicules. Transport. Mobilité. 
PEREIRA, D. B. S.; FERREIRA, W. R.

Reflexos das ocupações urbanas na mobilidade às margens da Rodovia Estadual GO-060 entre Goiânia (GO) e Trindade (GO)

\section{INTRODUÇÃO}

Os processos de urbanização por diversas tipologias de ocupação, têm seus reflexos no fluxo de viagens por diversos modos de transporte, tais como: carro/moto, caminhão leve/micro-ônibus, caminhão/ônibus, bitrem/rodotrem e na mobilidade urbana em região metropolitana. Neto (2002) comenta que, a organização do espaço é uma contribuição da geografia, e a rodovia é um elemento que se caracteriza, como elo entre os meios urbano e rural.

A rodovia tem um papel preponderante como um elemento de desenvolvimento e de interligação com os bairros em seu entorno, interagindo com as redes e os objetos que compõem a infraestrutura e os equipamentos urbanos, mostrando o caráter dinâmico na configuração da organização socioespacial.

As políticas públicas devem estar relacionadas aos meios de transporte e ao controle do uso do solo. Entretanto, na visão de Maricato (2000), nem sempre os planos urbanísticos são colocados em prática gerando graves problemas de circulação e uma má qualidade de vida.

Diante desse cenário, a pesquisa se justifica na necessidade de compreender e identificar as tipologias - comércio; indústria; área institucional; conjunto habitacional e condomínio horizontal, que compõem os recortes espaciais, caracterizadas como Polos Geradores de Viagens (PGVs). Esses pólos, segundo Portugal (2012, p. 6), são "empreendimentos de grande porte que atraem ou produzem grande número de viagens", principalmente pelos índices de motorização, geração de viagens e pelos diversos modos de transportes, que impactam de imediato no sistema viário e de circulação, e em uma forma mais ampla na mobilidade urbana. Tal afirmação é corroborada por Kneib (2004) ao reforçar a importância de se relacionar os impactos diretos no sistema viário, na ocupação do uso do solo trazendo reflexos na mobilidade, provenientes de empreendimentos geradores de viagens. De acordo com o Ministério das Cidades (BRASIL, 2006, p.19), "a mobilidade é um atributo associado à cidade; corresponde à facilidade de pessoas e bens na área urbana."

A cidade, por sua vez, incrementa um processo de desenvolvimento urbano/ metropolitano, articulado a partir das centralidades do centro urbano, para uma dimensão da escala interurbana, formando conglomerados de áreas conurbadas, motivadas pela expansão das redes viárias. Na visão de Sposito (2016), a centralidade não pode ser vista e nem 
PEREIRA, D. B. S.; FERREIRA, W. R.

Reflexos das ocupações urbanas na mobilidade às margens da Rodovia Estadual GO-060 entre Goiânia (GO) e Trindade (GO)

analisada de forma pontual na estrutura espacial, mas deve ser percebida, sentida e imaginada no contexto social sobre a vida urbana, e a implantação do sistema de transportes contribuiu para o fenômeno da espacialização urbana.

Nesse contexto, o objetivo geral consiste em analisar o quantitativo do número de viagens em pontos de contagem $(\mathrm{Km})$ na rodovia, a evolução do fluxo de viagens e do índice de mobilidade, em função das alterações espaciais ocorridas nas tipologias de ocupação, caracterizadas como PGVs as margens da rodovia GO 060, no trecho entre Goiânia e Trindade. Para identificar tais ocorrências, utilizou-se a metodologia proposta por Kneib (2004), adaptada em 6 (seis) etapas, a serem detalhadas para análise espaço-temporal e de redes, bem como a de Cardoso (2005) utilizada para o cálculo do índice de mobilidade e validação estatística.

\section{Delimitação das regiões de estudo: configuração espacial e redes viárias}

Para compreender a delimitação da área da pesquisa, a Figura 1 mostra a extensão de 18 km da Rodovia Estadual GO-060 entre as cidades de Goiânia e Trindade, no Estado de Goiás, que integra a Região Metropolitana de Goiânia (RMG).

Figura 1 - Mapa da Rodovia GO-060 com a delimitação das regiões de estudo e suas redes alimentadoras - Ano 2018

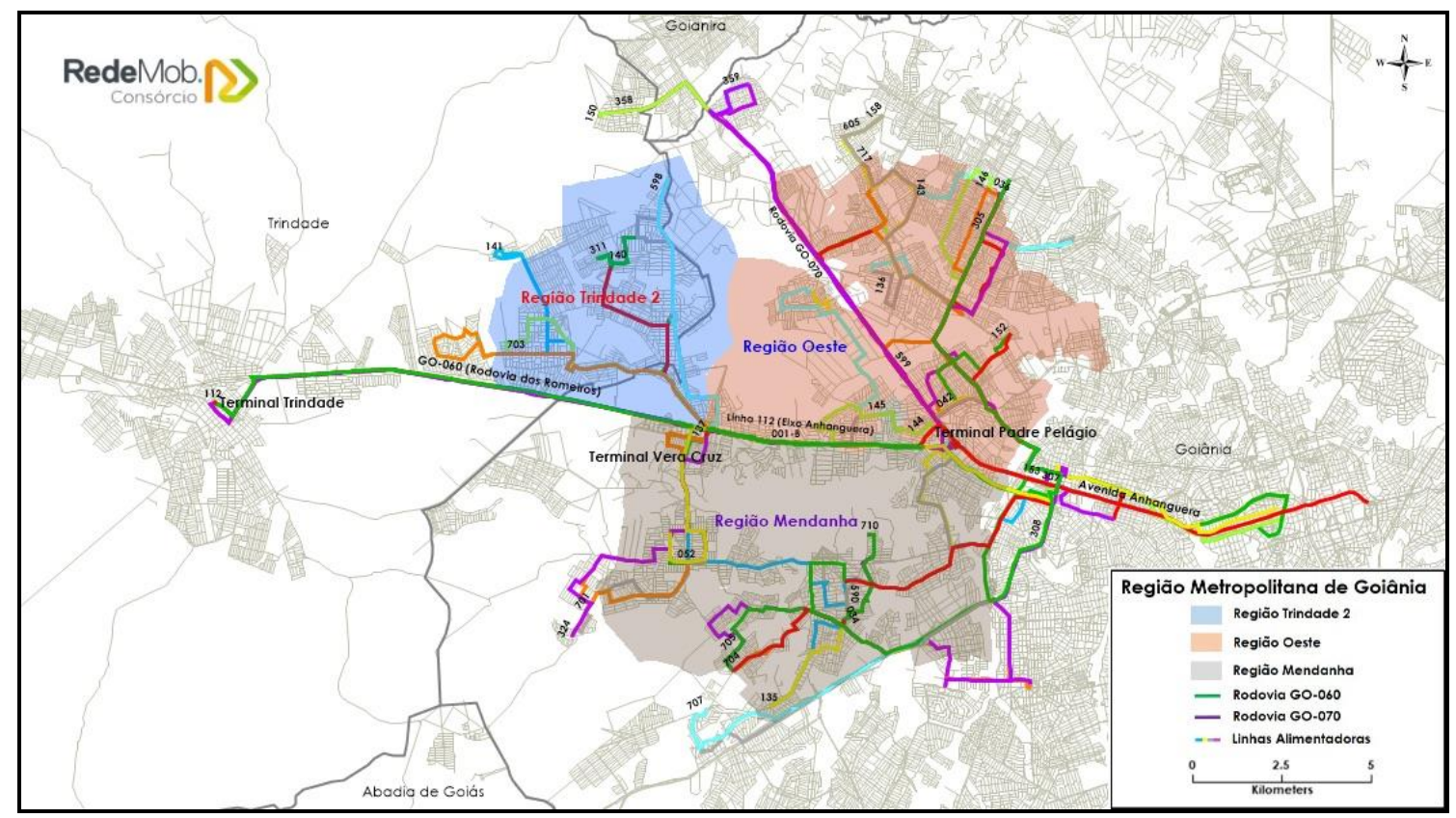

Fonte: RedeMob (2018).

Revista Cerrados, Montes Claros/MG, v. 18, n. 1, p. 189-219, jan./jun.-2020 
PEREIRA, D. B. S.; FERREIRA, W. R.

Reflexos das ocupações urbanas na mobilidade às margens da Rodovia Estadual GO-060 entre Goiânia (GO) e Trindade (GO)

A Figura 2 mostra a limitação dos recortes espaciais das Regiões Oeste/Mendanha e Trindade 2, dos Municípios de Goiânia e Trindade, respectivamente, que compõem a Região Metropolitana de Goiânia, ocupadas por diversas tipologias como: lotes residenciais (unidade padrão), lotes especiais (unidade diferenciada); conjuntos habitacionais; áreas ocupadas por posses; condomínios horizontais; comércio e indústrias, situadas na franja metropolitana dos Municípios de Goiânia e Trindade, considerando a linha divisória dos respectivos municípios distante de 5,5 Km da cidade de Goiânia e revelando a variação das redes de serviços e da ocupação espacial ao longo desse trecho. As áreas dos recortes espaciais foram delineadas e demarcadas em função do grau de proximidades da Rodovia GO-060 e para ser uma área representativa das características das ocupações espaciais e das redes viárias.

Figura 2 - Recortes espaciais dos Municípios de Goiânia e Trindade no entorno da Rodovia GO-060 - Ano 2018

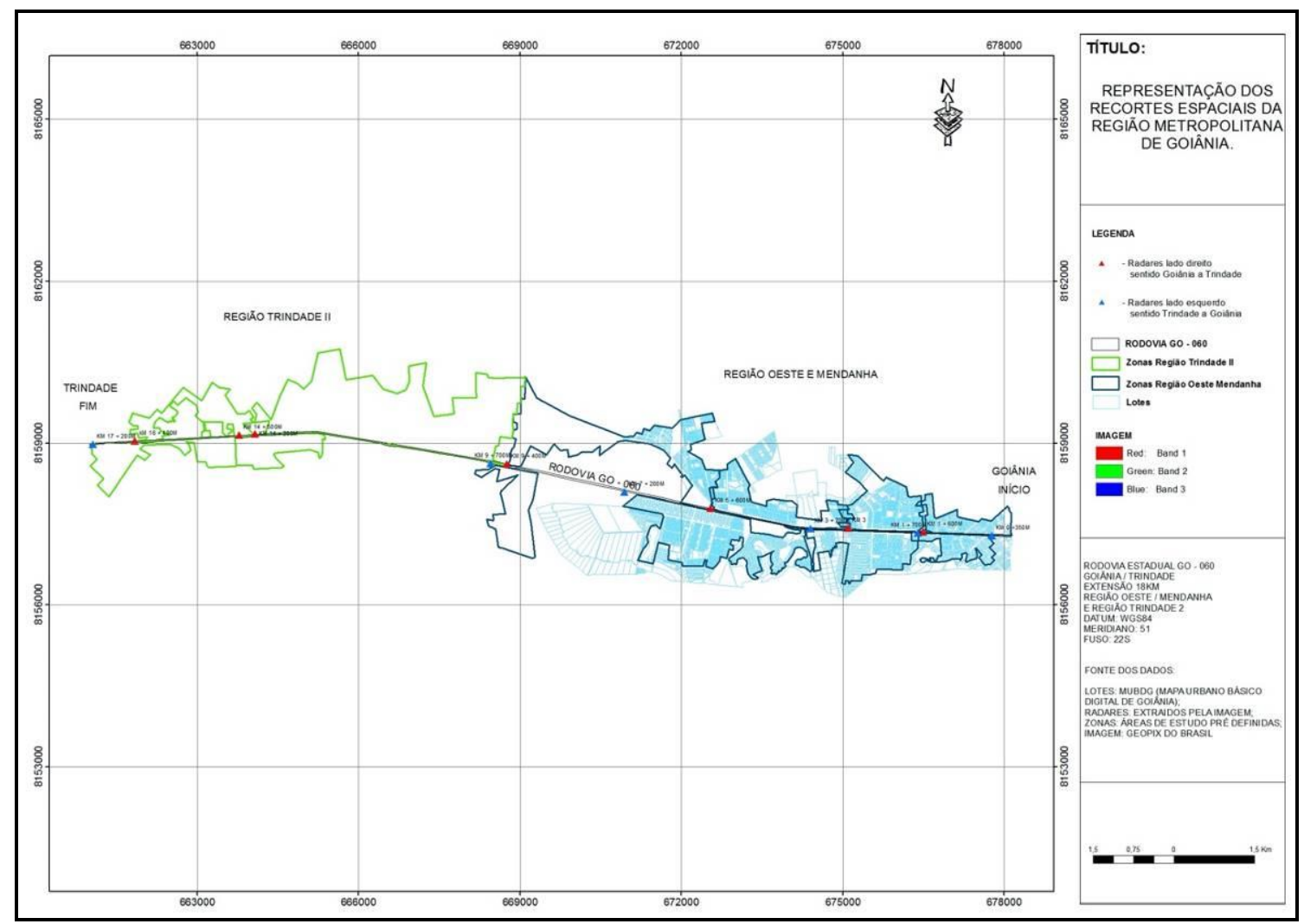

Fonte: Pereira (2018).

Os espaços ao longo do trecho rodoviário da GO-060, inseridos na área metropolitana se encontram em processo de conurbação entre as cidades de Goiânia e Trindade, notadamente nas Regiões Oeste/Mendanha e Trindade 2, respectivamente, gerando Revista Cerrados, Montes Claros/MG, v. 18, n. 1, p. 189-219, jan./jun.-2020 
PEREIRA, D. B. S.; FERREIRA, W. R.

Reflexos das ocupações urbanas na mobilidade às margens da Rodovia Estadual GO-060 entre Goiânia (GO) e Trindade (GO)

uma ocupação por diversas tipologias com características diferenciadas, que modificaram a estrutura espacial adjacente, criando-se uma ligação de redes de alta complexidade com alta taxa de geração de viagens. Esse fenômeno caracterizado por conurbação, segundo Ferrari (2004), ocorre em zona urbanizada que abrange mais de uma área urbana de forma contínua e agrupada, ou seja, verifica-se a fusão de duas ou mais zonas urbanizadas e compartilhadas.

Em relação ao recorte espacial/temporal, Hissa (2006, p.184) adverte que "para compreender a essência do espaço é preciso dirigir o olhar às suas origens, rediscutindo a natureza da observação", descobrindo o que "não está à vista" e o que "não está à mostra". A partir dessa leitura, pode-se inferir que nas pesquisas e no levantamento de dados tem-se a necessidade de um entendimento da temporalidade dos fenômenos e a necessidade de espacializá-los, apropriando os fluxos veiculares por meio das tipologias dos recortes espaciais.

Nessa concepção em atribuir as categorias de espaço e redes para o desenvolvimento deste estudo, evidenciou-se em analisar a ocupação do uso do solo e suas implicações no fluxo veicular, no deslocamento da população por diversos modos de transportes e nas questões da mobilidade urbana no entorno da rodovia para entender o movimento do espaço. Para Santos (2004, p. 153), “o espaço é, então, um verdadeiro campo de forças cuja aceleração é desigual. Daí porque a evolução espacial não se faz de forma idêntica em todos os lugares."

Isso demonstra que fatos aparentemente isolados têm implicações que influenciam diretamente no espaço e na configuração das redes. Nesse sentido, é preciso estabelecer periodizações tendo como foco as continuidades e as descontinuidades dos eventos históricos, que se manifestaram na Região Metropolitana da cidade de Goiânia, tendo a Rodovia Estadual GO-060 como via de ligação com a cidade de Trindade e bairros circunvizinhos. Assim, é preciso evidenciar as novas configurações espaciais e as redes que serão identificadas no desenvolvimento deste artigo.

A Região Metropolitana de Goiânia foi instituída pela Lei Complementar Estadual $\mathrm{n}^{\circ}$ 27, de 30 de dezembro de 1999 (GOIÁS, 1999). A composição da RMG foi alterada em 2004 e 2005, e, atualmente, a RMG é constituída por vinte municípios, segundo a alteração realizada pela Lei Complementar $n^{\circ} 78 / 2010$, e é caracterizada por intensa urbanização e 
PEREIRA, D. B. S.; FERREIRA, W. R.

Reflexos das ocupações urbanas na mobilidade às margens da Rodovia Estadual GO-060 entre Goiânia (GO) e Trindade (GO)

interdependência entre seus municípios, o que provoca um número de viagens diárias entre eles que extrapola a capacidade de planejamento e de gestão da mobilidade e acessibilidade.

A ideia de região urbana/metropolitana se confunde e expande na multiplicidade de fatores em conhecer os efeitos estruturais da realidade, a idealização dos diversos recortes espaciais e a expressão do pensamento geográfico como elemento preponderante, para explicar os contextos sociais, econômicos, naturais e políticos. (GOMES, 2008).

Nas Figuras 3 e 4 é possível visualizar os fluxos dos deslocamentos pendulares com destino e origem entre os municípios da sub-região Oeste da RMG, interligando com a cidade de Goiânia. Nessa sub-região, Trindade apresenta a maior polarização em relação aos movimentos pendulares por motivo de trabalho e/ou estudo.

Figura 3 - Fluxos pendulares por motivo de trabalho e/ou estudo com destino nos municípios da sub-região Oeste

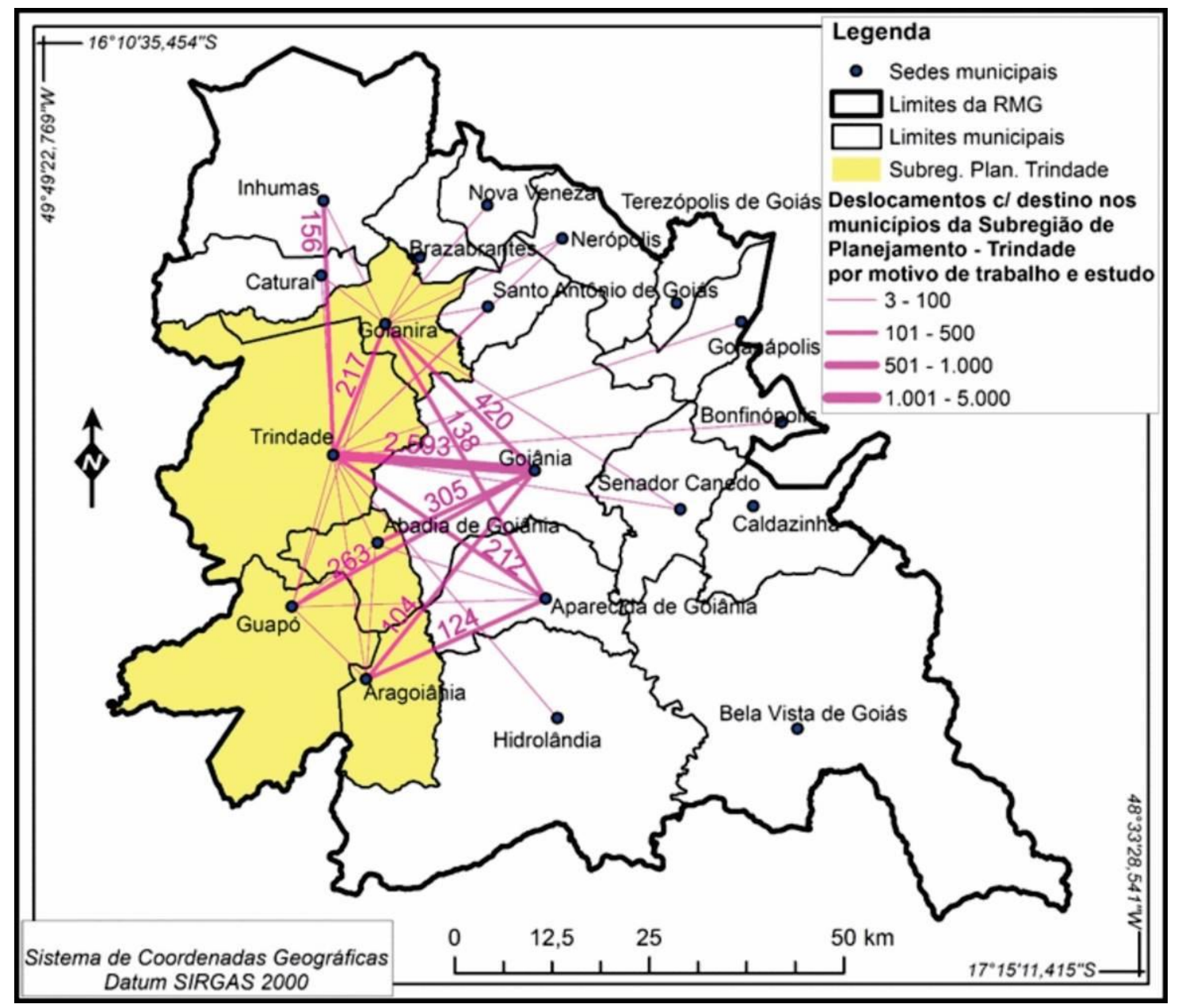

Fonte: Secretaria de Estado de Meio Ambiente, Recursos Hídricos, Infraestrutura, Cidades e Assuntos Metropolitanos - SECIMA (2018).

Revista Cerrados, Montes Claros/MG, v. 18, n. 1, p. 189-219, jan./jun.-2020 
PEREIRA, D. B. S.; FERREIRA, W. R.

Reflexos das ocupações urbanas na mobilidade às margens da Rodovia Estadual GO-060 entre Goiânia (GO) e Trindade (GO)

Figura 4 - Fluxos pendulares por motivo de trabalho e/ou estudo com origem nos municípios da sub-região Oeste

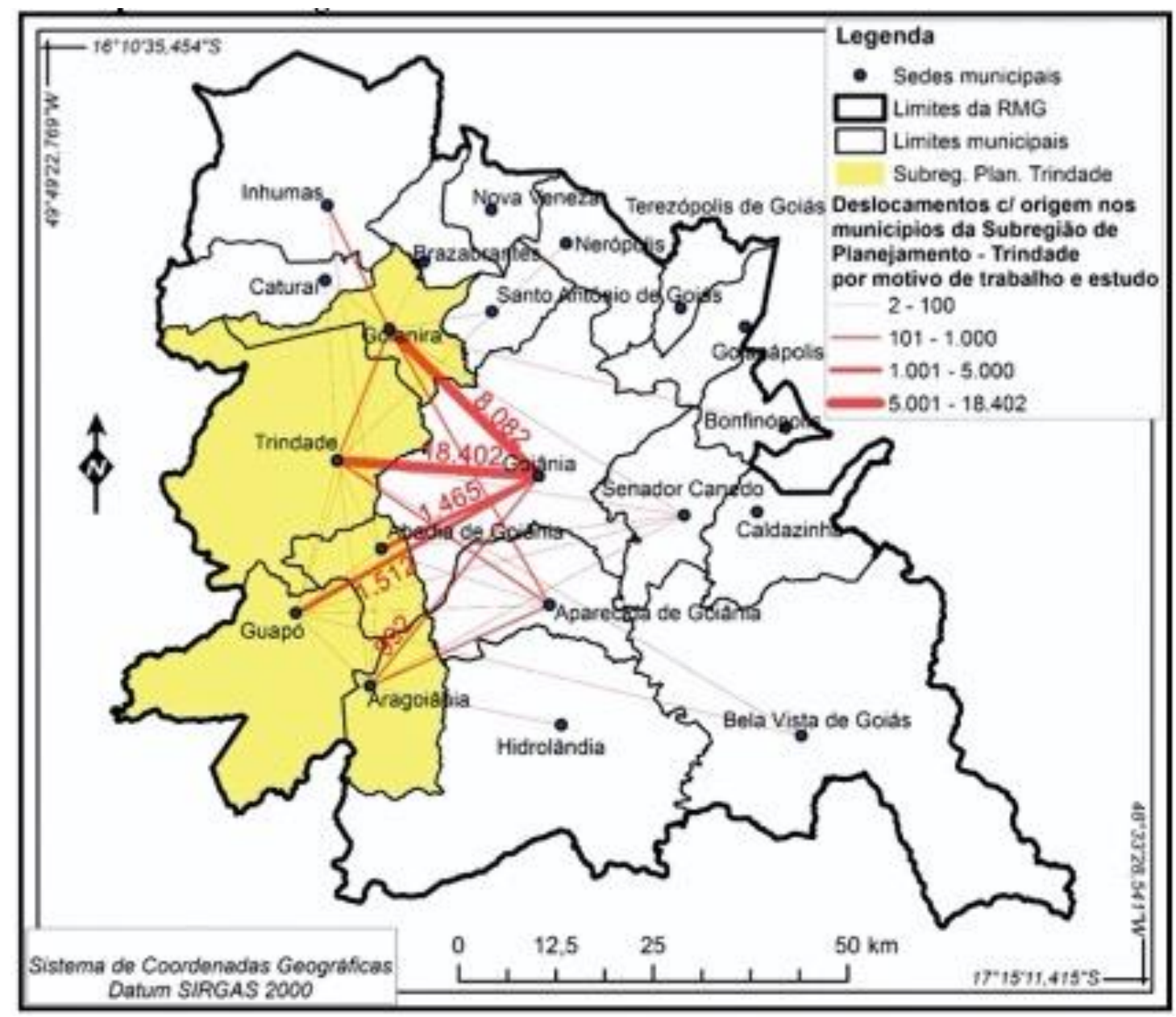

Fonte: SECIMA (2018).

A legenda das linhas que representa os fluxos está organizada nas respectivas classes com seus intervalos, mostrando a intensidade dos fluxos pendulares. Essas classes correspondem ao número de pessoas que se deslocam entre os municípios de Goiânia e Trindade, sendo um dos eixos mais intensos de integração na perspectiva da mobilidade urbana.

Observa-se, por meio dos dados de deslocamentos pendulares, que a intensidade predominante do fluxo é com origem na cidade de Trindade para Goiânia, inferindo que existe ainda uma polaridade marcante de Goiânia como polo atrativo de negócios e de estudos. Essa situação retrata a interdependência do processo de metropolização e da fluidez das vias de 
PEREIRA, D. B. S.; FERREIRA, W. R.

Reflexos das ocupações urbanas na mobilidade às margens da Rodovia Estadual GO-060 entre Goiânia (GO) e Trindade $(\mathrm{GO})$

deslocamento, que, neste caso, trata-se da Rodovia GO-060, utilizada como meio de ligação entre essas duas cidades, que integram a RMG.

Goiânia, capital do Estado de Goiás, não foge à regra brasileira em buscar soluções para compatibilizar a ocupação territorial em sua região metropolitana com políticas públicas que impactam na mobilidade, interferindo no deslocamento das pessoas com qualidade. É uma cidade que, segundo o censo de 2010 do Instituto Brasileiro de Geografia e Estatística (IBGE), conta com uma população de 1.302 .001 habitantes e a região metropolitana com 2.052.896.

Nesse processo evolutivo de fluxo migratório de ocupação, em áreas de transição urbana/metropolitana, a Rodovia Estadual GO-060, denominada Rodovia dos Romeiros, é margeada por uma estrutura espacial fragmentada, ora com diversos bairros variando com áreas de alto adensamento demográfico, e outra, com bolsões vazios, mostrando a diversidade na estrutura espacial da região.

\section{Organização do espaço em região metropolitana: aspectos urbano e rural no entorno da rodovia}

As regiões metropolitanas das cidades passam por uma transformação dinâmica na sua estrutura socioespacial, proveniente do incremento dos fluxos de pessoas e de veículos, compartilhando os espaços a partir das categorias que definem forma, função, estrutura e processo empregados na relação cotidiana da sociedade com efeitos na mobilidade urbana.

Segundo Santos (1992), essas categorias definem a estrutura espacial em relação aos interesses da sociedade e devem ser estruturadas e compreendidas ao longo do tempo, em um processo de transformação histórica, onde as dimensões do tempo, espaço e redes devem ser analisadas, como foco da organização espacial.

As práticas espaciais originadas e vividas no contexto de (re)produção do espaço retratam as diferenciações reproduzidas em cada momento, na concepção e na implantação de atividades de comércio, indústria e habitações nas margens de rodovia, exigindo-se um controle na administração da organização espacial, tornando-se um desafio para a implantação de políticas públicas, voltadas para o planejamento urbano e de transportes.

No contexto dessa dinâmica, Corrêa (2008), esclarece que as ocorrências das práticas espaciais podem expressar um conjunto de ações localizadas em caráter 
PEREIRA, D. B. S.; FERREIRA, W. R.

Reflexos das ocupações urbanas na mobilidade às margens da Rodovia Estadual GO-060 entre Goiânia (GO) e Trindade (GO)

complementar sobre a configuração do espaço, a serem identificadas com as características de urbanização, das tipologias, das redes viárias e das atividades em torno da rodovia.

Essa realidade se agrava de forma negativa, sobretudo por falta de critérios urbanísticos e de aplicação de legislação específica para o controle sistemático do uso do solo e da ampliação de redes viárias às margens de rodovia, sem aprovação dos órgãos gestores, motivados pela especulação imobiliária e pela ocupação desordenada e desenfreada. Com isso, tornam-se necessários estudos para compatibilizar a ocupação e o uso do espaço com o deslocamento das pessoas, tendo a rodovia como eixo estruturante no desenvolvimento da região metropolitana, como mostra a Figura 5.

Figura 5 - Intervenções na ocupação espacial e redes da Rodovia GO-060 no município de Goiânia - Ano 2016

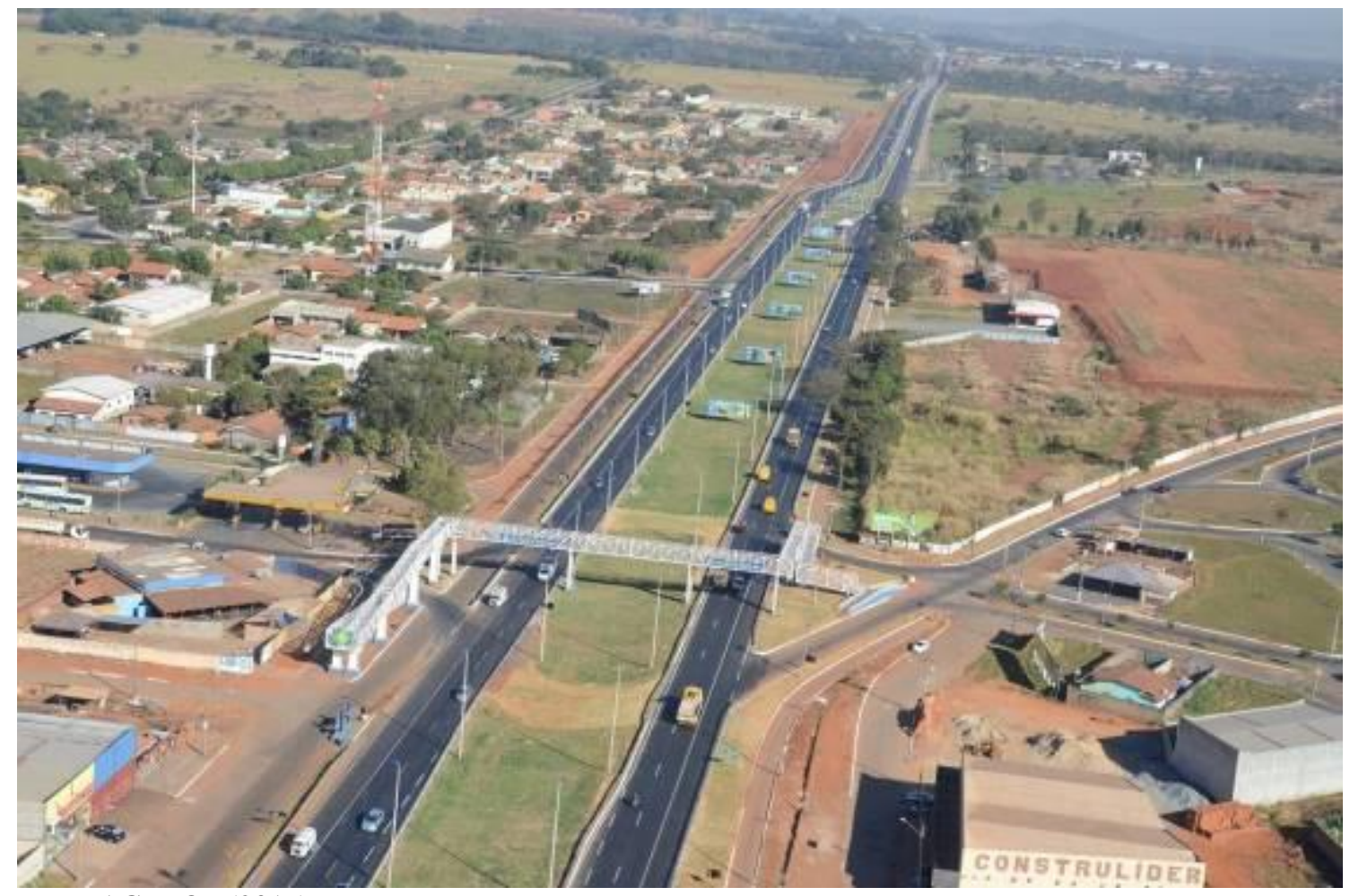

Fonte: AGETOP (2016).

Nesse contexto, Ferreira (2002), ressalta que

[U]m dos condicionantes básicos na determinação na qualidade de vida urbana e que direciona de forma definitiva as estratégias de planejamento, na maioria das cidades, é a dotação de usos diversos dos espaços públicos, através das legislações de uso e ocupação do solo, pois é responsável pela dinâmica da evolução sócio-espacial, que é constante e contínua, sob diversas forma e entre diferentes instâncias da sociedade. (FERREIRA, 2002, p. 245).

Revista Cerrados, Montes Claros/MG, v. 18, n. 1, p. 189-219, jan./jun.-2020 
PEREIRA, D. B. S.; FERREIRA, W. R.

Reflexos das ocupações urbanas na mobilidade às margens da Rodovia Estadual GO-060 entre Goiânia (GO) e Trindade (GO)

Vesentini (2005) comenta que as grandes cidades sofrem um processo de transformação contínua e de polarização, influenciando a formação de novos espaços com expansão de suas periferias para o meio rural, gerando o fenômeno de conurbação, isto é, a integração entre duas cidades com dimensões diferenciadas, mas compartilhadas e influenciadas em suas ocupações e nas redes viárias, criando- se uma região metropolitana.

Em decorrência disso, o grau de urbanização vai depender dos mecanismos de controle do uso do solo, do incentivo pela oferta dos meios de transporte público e privado, do investimento econômico por parte dos empresários, comerciantes, industriais e habitantes, que integram e influenciam os aspectos da mobilidade no entorno de uma rodovia.

Segundo Neto (2002), o espaço, uma vez habitado, promove a relação da sociedade com os meios urbano/rural, integrando-os por meio dos elementos que compõem a estrutura espacial, como: comércios, residências, indústrias, equipamentos urbanos; e o conjunto do sistema viário, composto por: ruas, avenidas, viaduto, terminais de transbordo, pontos de ônibus, calçadas, ciclovias e passarelas de pedestres.

Nessa concepção, a organização do espaço rural tem suas características específicas fundamentadas sob a influência do poder estatal, enquanto a organização do espaço urbano se encontra definida como parte essencial da geografia urbana composta pelo sistema de ruas, avenidas, equipamentos urbanos, atividades funcionais e habitações relacionando-se entre si, permitindo a análise da dinâmica ocupacional do uso do solo.

Acerca da diferenciação conceitual sobre esses espaços, Soares e Araújo (2009), esclarecem que

[O] campo e a cidade poderiam ser identificados como uma realidade material, enquanto que as respectivas categorias rural e urbano a eles associadas correspondem a uma realidade social produzida nesses espaços. Em outras palavras, poderíamos afirmar que são os sujeitos, definidos ora como rurais ora como urbanos, que imprimem significados aos espaços em que vivem, dotando-os de elementos que possibilitam a identificação e distinção entre o mundo rural e urbano. (SOARES; ARAÚJO, 2009, p. 206).

Os meios urbano e rural se constituem em um elo entre os espaços geográficos, notadamente em região metropolitana. Nesse sentido, Sposito (1994) destaca que não existe mais diferenciação nos modos de produção entre cidade e meio rural, tudo se relaciona e se articula na concepção de totalidade entre dois espaços distintos, coexistindo-se mediante redes viárias, equipamentos urbanos, comércio, indústria e habitação, com uma contribuição 
PEREIRA, D. B. S.; FERREIRA, W. R.

Reflexos das ocupações urbanas na mobilidade às margens da Rodovia Estadual GO-060 entre Goiânia (GO) e Trindade (GO)

significativa para a análise da organização espacial em identificar as interações espaciais, os objetos e os fluxos veiculares e de comunicação que se interagem na formação socioespacial.

Em relação à organização do espaço urbano, Silveira (1991 apud PORTUGAL, 2012, p.27) argumenta: "ressalta-se a relevância da presença de polos geradores de viagens causando, muitas vezes, alteração do uso do solo, da densidade, da ocupação física do solo e do valor dos terrenos", mostrando a multiplicidade e a diversidade espacial dos PGVs com implicações no fluxo de veículos integrados na rede de transportes e na mobilidade urbana.

\section{Mobilidade urbana versus PGV: conflitos e contradições}

Percebe-se que o quadro histórico da rodovia não foi estático, desde a sua concepção vem comparecendo a relação de conflitos e contradições na sua estrutura espacial e viária, influenciados pelos PGVs, implantadas ao longo do trecho Rodoviário da GO-060. Os PGVs, em função de suas características, norteiam a competitividade na estrutura espacial e o comprometimento da mobilidade urbana influenciado por um processo ininterrupto de intervenção no tecido urbano/metropolitano,

Esse fenômeno é abordado por Portugal (2012), retratando as transformações que ocorrem no ambiente urbano/rural e produzem impactos nos sistemas de transporte e a interação dos meios de transportes com as tipologias do uso do solo, destacando os PGVs que se manifestam pelas suas atividades, atratividade sobre a população e pelo número de viagens realizadas. Desta forma, os PGVs se caracterizam por serem elementos impactantes, repercutindo seus efeitos nas categorias de espaço e tempo e sua potencialidade será identificada no quantitativo do número de viagens e na mobilidade urbana.

Para contribuir e complementar com a discussão sobre dinâmica da estrutura do espaço e da mobilidade, vários estudos estão relacionados aos PGVs, assim como conceitos e definições de diversos autores. Segundo Kneib (2004), tais polos têm o poder de impactar direta e indiretamente uma área de influência no entorno do empreendimento, levando em consideração as alterações do uso do solo, os componentes do sistema viário e das características dos PGVs. A Figura 6 retrata esses elementos no que tange aos critérios urbanísticos, na utilização dos modos de transporte e no número de viagens geradas a partir da dinâmica na relação uso do solo versus sistema viário. 
PEREIRA, D. B. S.; FERREIRA, W. R.

Reflexos das ocupações urbanas na mobilidade às margens da Rodovia Estadual GO-060 entre Goiânia (GO) e Trindade $(\mathrm{GO})$

Figura 6 - Fluxo veicular por diversos modos de transporte da Rodovia GO-060 no município de Trindade - Trecho: Goiânia - Trindade - Ano 2016

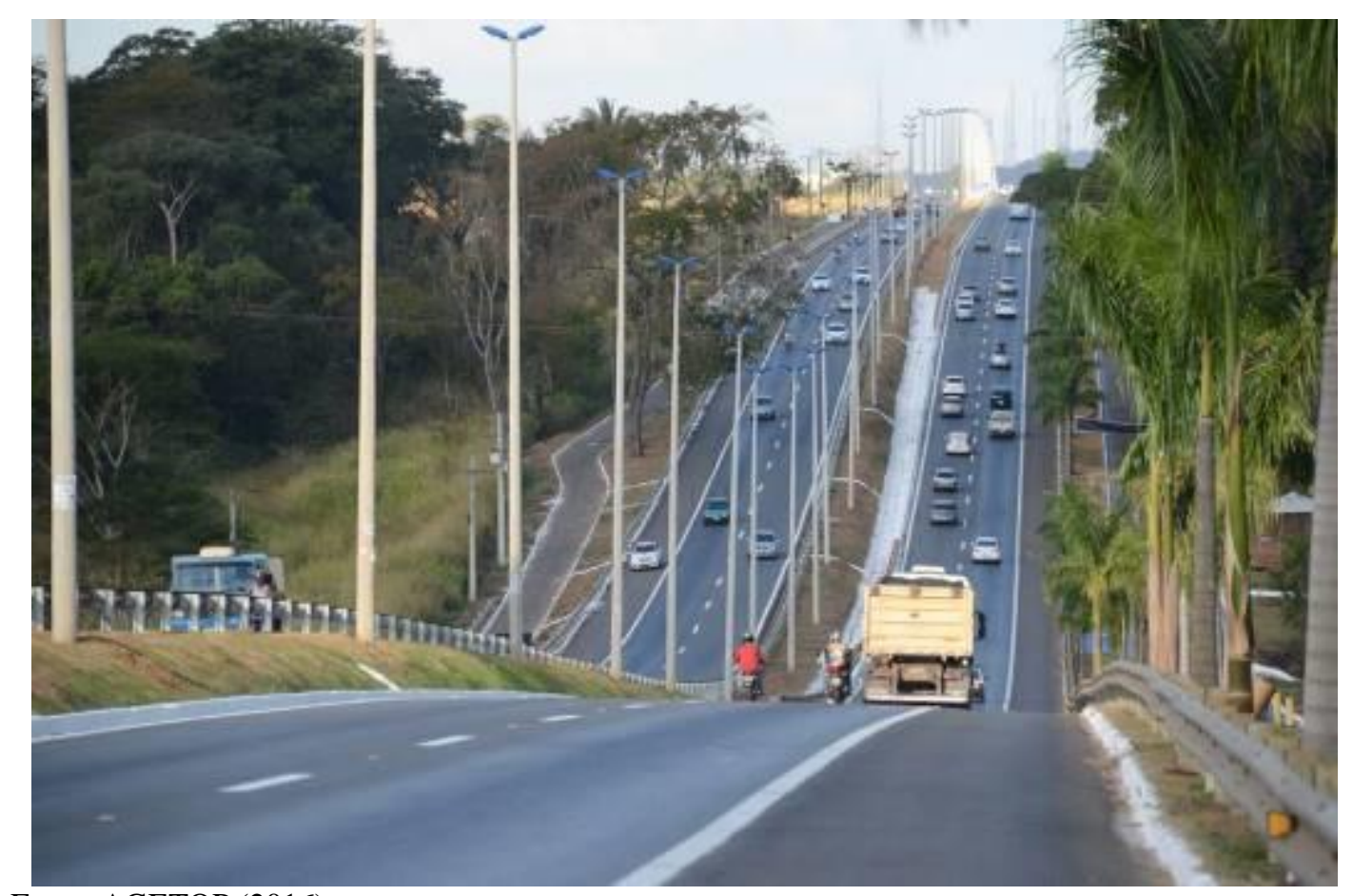

Fonte: AGETOP (2016).

Nesse contexto, Kneib (2008) ressalta que a estrutura espacial das cidades, tem seus reflexos na mobilidade urbana, com implicações no sistema viário e de transportes. Portugal e Goldner (2003) consideram que a delimitação da área de influência de um empreendimento nas margens da rodovia permite, por meio da caracterização e da identificação de PGVs, quantificar o fluxo veicular por diversos modos de transporte.

A mobilidade, portanto, traduz relações dos indivíduos com o espaço - seu local de vida - com os objetos e meios empregados para que o deslocamento aconteça. Daí surge a necessidade de compreender e analisar os elementos intervenientes que compõem a mobilidade como o uso do solo e a geração do número de viagens. De acordo com o Ministério das Cidades (BRASIL, 2006, p.19), "a mobilidade é um atributo associado à cidade; corresponde à facilidade de deslocamento de pessoas e bens na área urbana."

Observa-se que esta análise não se esgota apenas nos aspectos pontuais da estrutura espacial e na geração de fluxo de viagens pelos diversos modos de transporte, mas avalia, sobretudo, o desenvolvimento socioeconômico da região e a qualidade de vida da população. Nas palavras de Kneib (2012, p. 71), “As cidades enfrentam, a cada dia, questões 
PEREIRA, D. B. S.; FERREIRA, W. R.

Reflexos das ocupações urbanas na mobilidade às margens da Rodovia Estadual GO-060 entre Goiânia (GO) e Trindade (GO)

mais difíceis e desafiadoras relacionadas à mobilidade das pessoas, que vêm comprometendo a qualidade de vida urbana".

Tais elementos corroboram a necessidade de estudos que consigam comprovar e analisar, quantitativamente, a evolução das ocupações espaciais das regiões em estudo, numa série histórica, com a análise do fluxo do quantitativo de viagens e do índice de mobilidade, em função das áreas de ocupação por diversas tipologias caracterizadas por PGVs.

\section{Métodos de pesquisa}

Esta pesquisa consistiu em avaliar os impactos provenientes das tipologias de ocupação, caracterizadas como PGVs na mobilidade urbana no contexto de rodovia. A Figura 7 apresenta a estrutura de análise espaço-temporal e de redes desenvolvida de acordo com a adaptação da metodologia (i) proposta por Kneib (2004):

Figura 7 - Estrutura de Análise Espaço -Temporal e Redes

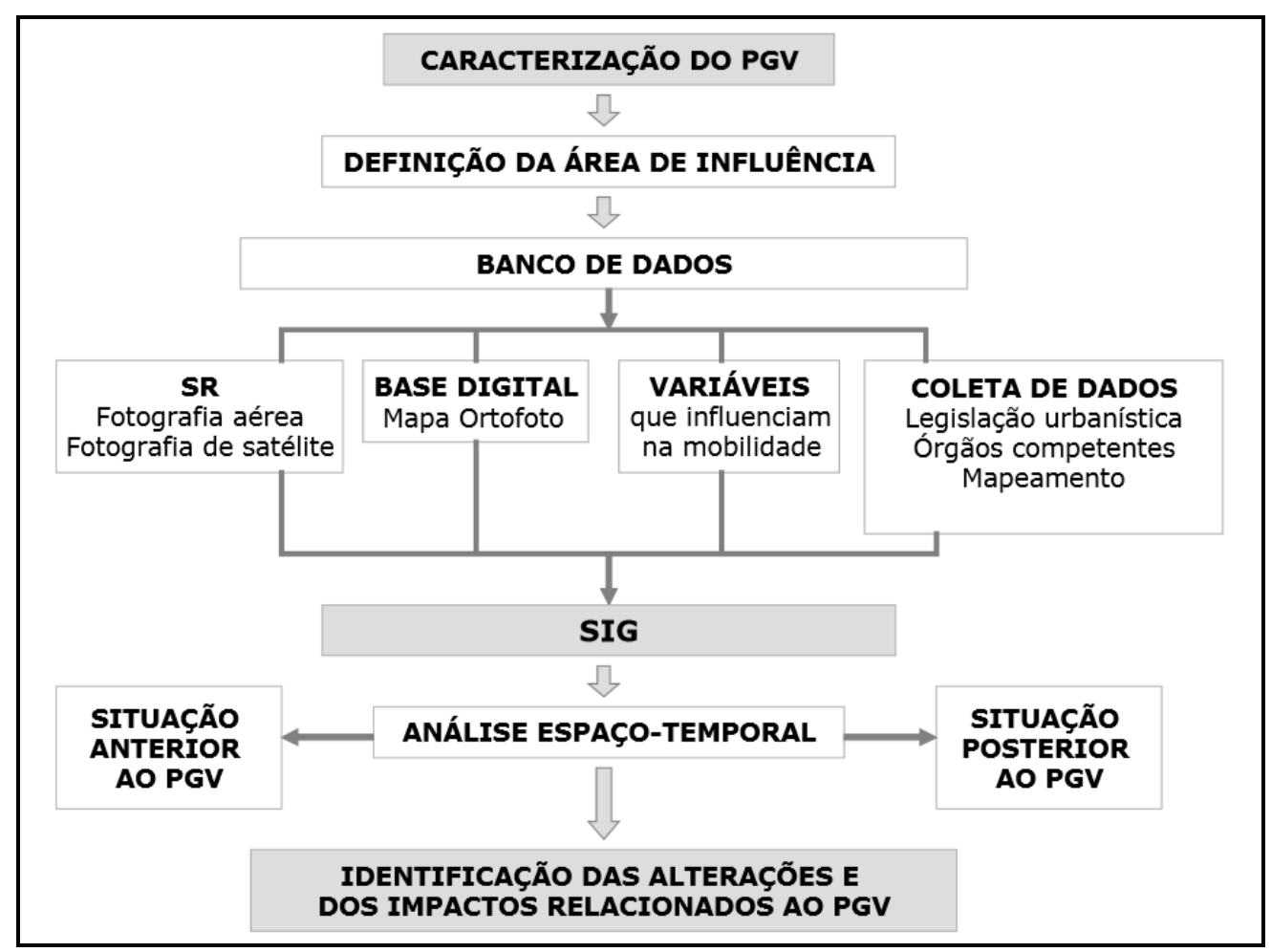

Fonte: Kneib (2004).

A estrutura de análise desenvolvida divide-se sinteticamente em seis etapas, descritas a seguir: i) delimitação da área de estudo por meio de recorte espacial e definição Revista Cerrados, Montes Claros/MG, v. 18, n. 1, p. 189-219, jan./jun.-2020 
PEREIRA, D. B. S.; FERREIRA, W. R.

Reflexos das ocupações urbanas na mobilidade às margens da Rodovia Estadual GO-060 entre Goiânia (GO) e Trindade (GO)

das variáveis, identificando-se os polos geradores de viagens (PGVs), segundo os parâmetros adotados pelo Denatran (2001) e as variáveis de ocupação do uso do solo por diversas tipologias; ii) banco de dados com mapas urbano digitais georreferenciados; iii) coleta de dados: imagens ortofoto e população dos bairros que compõem as Regiões Oeste/Mendanha e Trindade 2 pelo Instituto Brasileiro de Geografia e Estatística (IBGE, 2010); fluxo de veículos por diversos tipos de modais de transporte do ano de 2013 a 2016 pela Agência Goiana de Transportes e Obras ( AGETOP, 2017); iv) elaboração de cálculo e análise do índice de mobilidade, segundo conceitos de Cardoso (2005); v) integração das imagens para análise das situações antes e depois dos empreendimentos (PGVs); e vi) uso de ferramentas que possibilitem a análise quantitativa e a identificação de padrões e tendências. Na Figura 8 , observa-se o roteiro básico para a elaboração de estudos de impacto de polos geradores de viagens, proposto pelo DENATRAN (2001):

Figura 8 - Roteiro básico proposto pelo DENATRAN (2001)
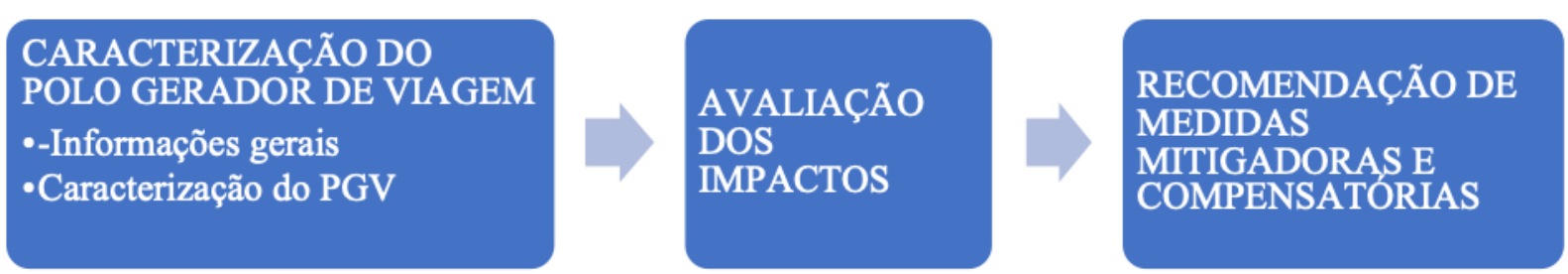

Fonte: adaptado de DENATRAN (2001).

A metodologia (ii) utilizada por Cardoso (2005) propõe analisar a evolução da mobilidade relacionada à composição da população. Para o cálculo do índice de mobilidade, utilizou-se o conceito de que mobilidade se relaciona com o número de viagens/habitante. Os resultados encontrados a partir da aplicação das metodologias (i e ii) permitem avaliar o grau de mobilidade urbana em torno da rodovia.

\section{Estudo de caso}

Para o estudo de caso a ser aplicado, as etapas metodológicas (i e ii) compreendem as Regiões Oeste/Mendanha e Trindade 2 dos Municípios de Goiânia e Trindade do Estado de Goiás, respectivamente. Em relação ao contexto da frota veicular, houve uma evolução de 28,68\% e 80,01\% nos municípios de Goiânia e Trindade, 
PEREIRA, D. B. S.; FERREIRA, W. R.

Reflexos das ocupações urbanas na mobilidade às margens da Rodovia Estadual GO-060 entre Goiânia (GO) e Trindade $(\mathrm{GO})$

respectivamente, segundo o DENATRAN (2017); no contexto populacional, por sua vez, essa evolução foi apenas de 11,26\% e 14,26\%, de acordo com o IBGE (2017).

Para se entender espaço e rede, como categoria e conceito, optou-se por trabalhar em um estudo de caso da Região Metropolitana de Goiânia, que engloba uma região conurbada entre as cidades de Goiânia e Trindade com interferências no processo de urbanização e na mobilidade urbana em torno da Rodovia Estadual GO-060.

A Prefeitura Municipal de Goiânia (2007) e a Prefeitura Municipal de Trindade (2008), se organizaram em diversas escalas de fluxos de transporte de pessoas e bens, com inúmeros deslocamentos pendulares diários, constituindo-se em pontos de conexão de rede de centralidades ativas e dinâmicas. Essa rede foi apoiada por uma estrutura viária de funcionalidade local e regional, tornando-se um grande desafio para esses municípios em identificar as viagens pendulares motivadas pelo deslocamento da população.

A centralidade foi identificada a partir da sua atratividade e ao mesmo tempo, por meio de ações articuladas, estabelecendo uma relação de causa e efeito, para análise e compreensão da mobilidade urbana/metropolitana. Nesse contexto, vários autores têm contribuído para a compreensão da dinâmica espacial e na análise do fluxo/volume de tráfego, com reflexos no sistema viário e na mobilidade urbana, em relação aos aspectos estruturais do uso do solo e das redes viárias, que integram as Regiões Oeste/Mendanha e Trindade 2, objeto de estudo de caso.

Entende-se "espaço urbano como qualquer outro objeto social que pode ser abordado segundo um paradigma de consenso ou de conflito" (CORRÊA, 1995, p. 1) e se manifesta com o espaço urbano fragmentado e articulado por intermédio da ação dos agentes públicos e privados envolvidos na produção e reprodução da ocupação espacial.

Por sua vez, Vasconcellos (2001) define três técnicas específicas de intervenção que controlam o espaço viário: planejamento urbano, transporte e circulação que se relacionam com o uso do solo, a estrutura viária, a circulação e os meios de transporte.

De acordo com Raffestin (1993), o espaço, na condição de matéria-prima natural, é um produto em transformação, resultante da configuração imposta pela ação social com seus reflexos no espaço e um local de possibilidades, que se traduz pelo interesse da sociedade.

Conforme Pons e Reynés (2004), o modelo de desenvolvimento urbano descentralizado tem transferido a população, o comércio, os serviços e a atividade industrial 
PEREIRA, D. B. S.; FERREIRA, W. R.

Reflexos das ocupações urbanas na mobilidade às margens da Rodovia Estadual GO-060 entre Goiânia (GO) e Trindade (GO)

em direção às áreas periféricas das cidades, gerando grandes distâncias de deslocamento. Vasconcellos $(1996,2013)$ mostra que a implantação de PGVs, o índice de motorização e a oferta de meios de transporte, impactam as condições atuais de mobilidade.

O Manual de Engenharia de Tráfego da Companhia de Engenharia de Tráfego (CET, 1977, p.11) entende por volume de tráfego "o número de veículos que passa por uma determinada secção de uma via, na unidade de tempo”. Em relação à determinação do volume de tráfego, o professor Akishino (2004) explica que os fluxos de tráfego apresentam mutações contínuas ao longo dos meses do ano, principalmente em rodovias, e que a contagem de veículos é um fator essencial para o estudo.

\section{Resultados e discussão}

O estudo de caso a ser aplicado nas etapas metodológicas (i e ii) compreende as margens da Rodovia Estadual GO- 060, como eixo estruturante, a partir do $\mathrm{Km} 00$ ao Km 18, compreendendo as Regiões Oeste/Mendanha e Trindade 2, respectivamente.

Por se tratar de região extensa e com características morfológicas diversas e heterogêneas na estrutura espacial, a caracterização das Regiões Oeste/Mendanha e Trindade 2 foi apoiada na interpretação conceitual proposta por Ferrara (1999), procurando-se compreender as transformações das ocupações do uso do solo nessas regiões, apoiando-se nas tipologias do solo urbano e na imagem física do recorte espacial. Para a obtenção dos dados, compreendeu-se a pesquisa em três etapas de acordo com Pereira e Ferreira (2018): (i) análise da ocupação espacial; (ii) análise do fluxo veicular; e (iii) análise da mobilidade.

\section{Etapa (i) - Análise da Ocupação Espacial}

Consistiu em analisar a ocupação espacial por meio das tipologias identificadas na legenda das Figuras 9 e 10 limitando-se a uma área de recorte espacial de 25.364.900m2, que representa 37\% da área total das Regiões Oeste e Mendanha, localizadas na zona limítrofe e conurbada com o município de Trindade e compõem a Macrozona Construída no perímetro urbano da cidade de Goiânia (GO), de acordo com o Plano Diretor de 2007 (PREFEITURA MUNICIPAL DE GOIÂNIA, 2007). 
PEREIRA, D. B. S.; FERREIRA, W. R.

Reflexos das ocupações urbanas na mobilidade às margens da Rodovia Estadual GO-060 entre Goiânia (GO) e Trindade (GO)

Figura 9 - Regiões Oeste e Mendanha do município de Goiânia - Ano 2011

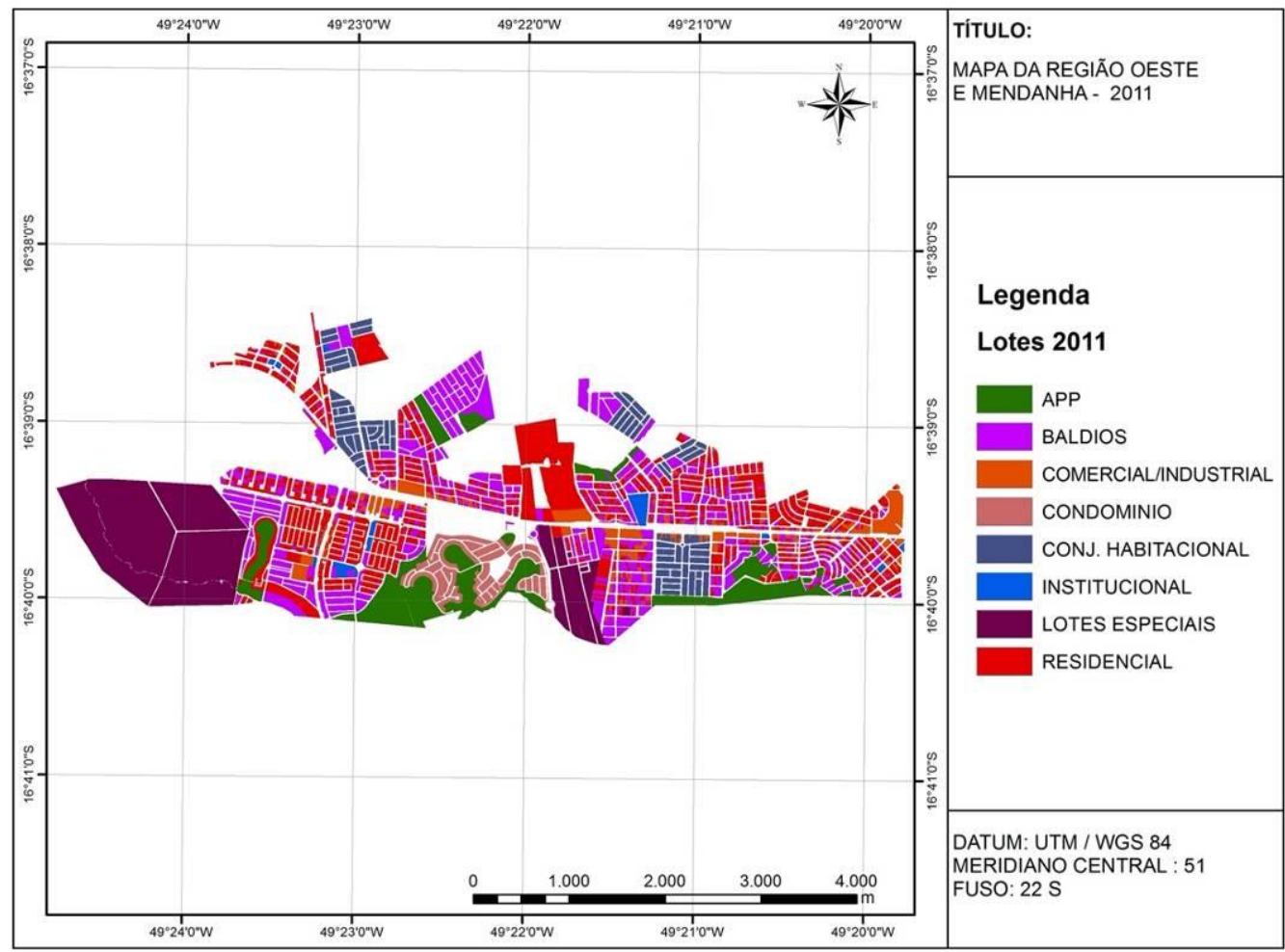

Fonte: Pereira e Ferreira (2018).

Figura 10 - Regiões Oeste e Mendanha do município de Goiânia - Ano 2016

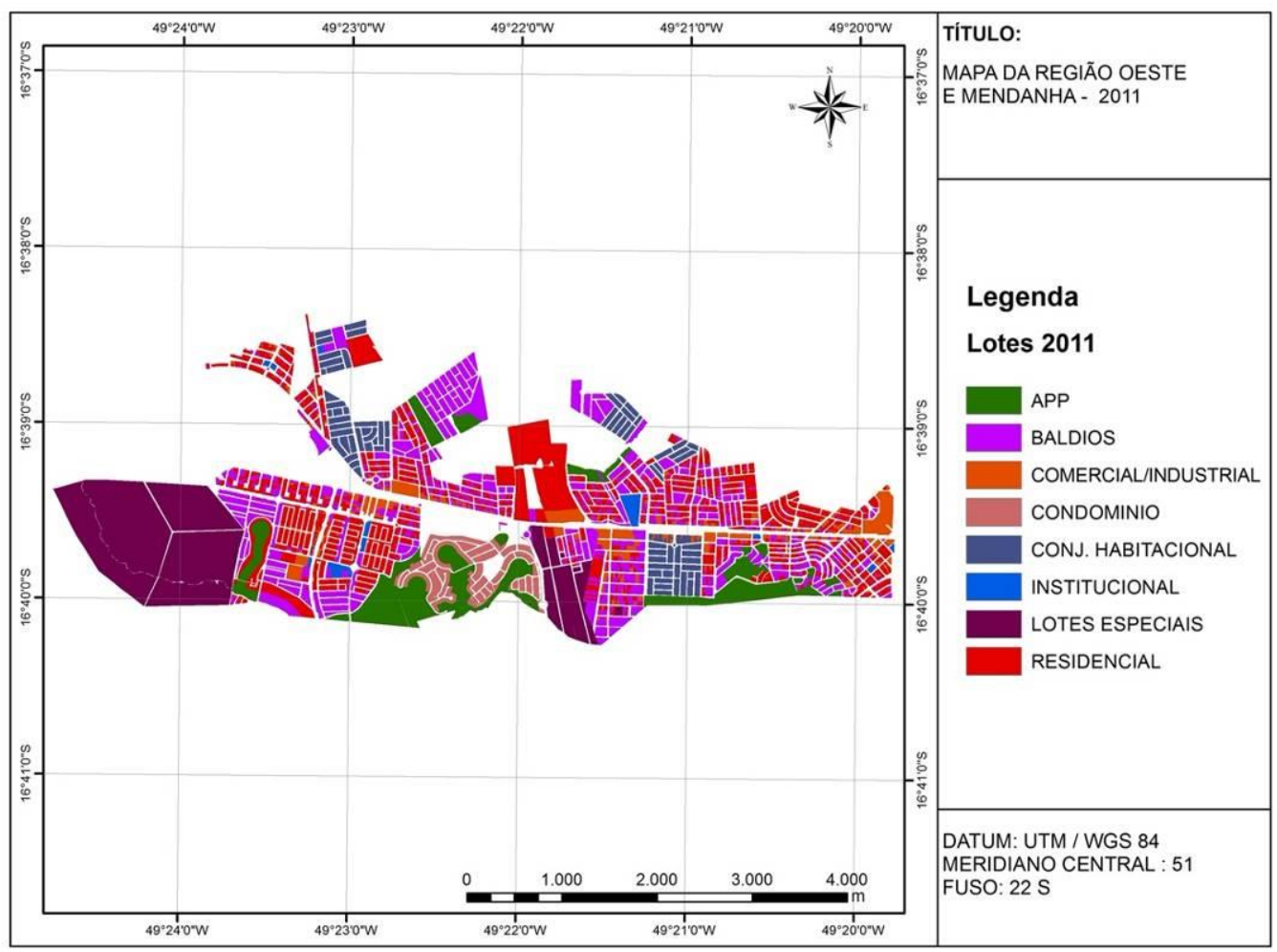

Fonte: Pereira e Ferreira (2018).

Revista Cerrados, Montes Claros/MG, v. 18, n. 1, p. 189-219, jan./jun.-2020 
PEREIRA, D. B. S.; FERREIRA, W. R.

Reflexos das ocupações urbanas na mobilidade às margens da Rodovia Estadual GO-060 entre Goiânia (GO) e Trindade (GO)

Para o cálculo e visualização das alterações espaciais ocorridas entre os anos de 2011 e 2016, para as Regiões Oeste e Mendanha, foram elaborados mapas denominados cheios e vazios, com base em imagens de levantamento aerofotogramétrico digital e georreferenciada do perímetro de Goiânia. A partir daí, foram identificados o quantitativo de unidades de cada área de lote para cada tipologia e calculadas as projeções das áreas construídas e suas diferenças com a utilização do software QGIS, conforme constam no Gráfico 1.

Gráfico 1 - Acréscimo das áreas de ocupação (\%) para as tipologias entre os anos de 2011 e 2016, Regiões Oeste e Mendanha

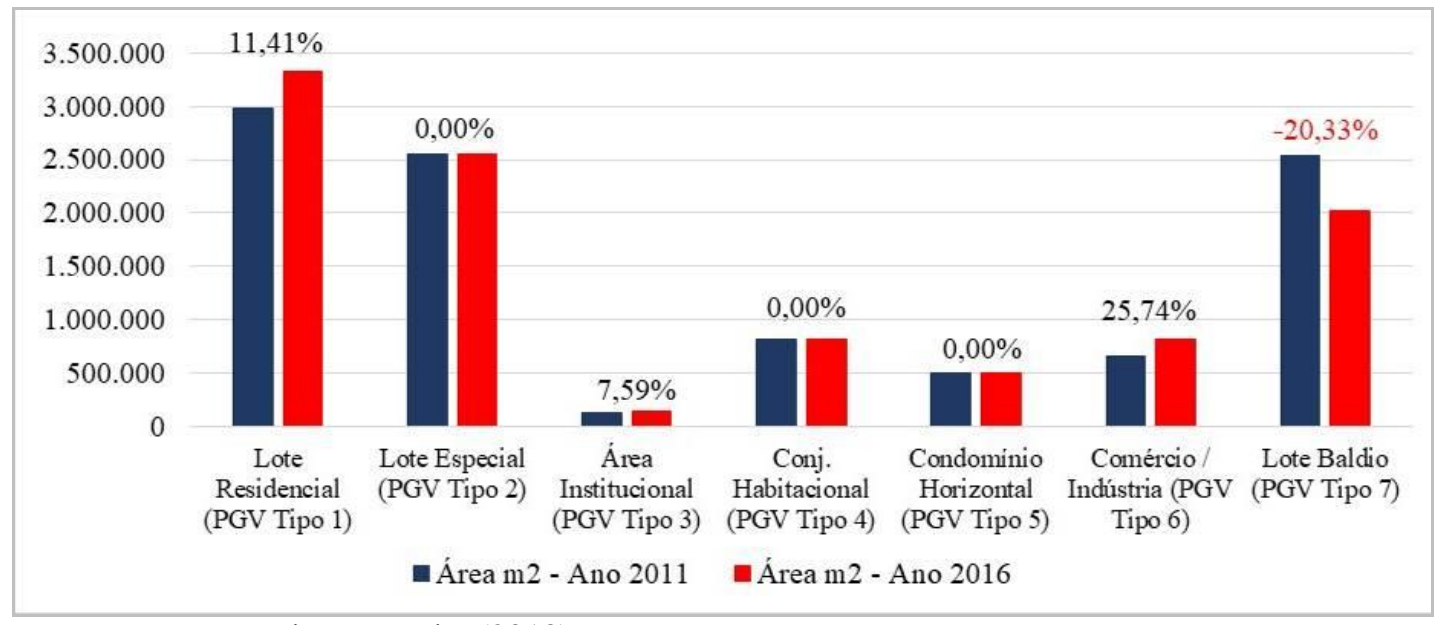

Fonte: Pereira e Ferreira (2018).

Os resultados do Gráfico 1 mostram as diferenças em áreas de ocupação entre os anos de 2011 e 2016, com predominâncias para a implantação de Comércio/Indústria - PGV Tipo 6 (25,74\%); Lote Residencial - PGV Tipo 1 (11,41\%); Área Institucional - PGV Tipo 3 (7,59\%); e um decréscimo em Lote Baldio - PGV Tipo 7 de (20,33\%); e para os PGVs: Lote Especial - Tipo 2, Conjunto Habitacional - Tipo 4 e Condomínio Horizontal - Tipo 5, não houve alteração na área construída. Essa configuração espacial retrata a dinâmica territorial no entorno da Rodovia Estadual GO-060, nas Regiões Oeste e Mendanha do Município de Goiânia.

As tipologias identificadas na legenda da Figura 11 limitam uma área de recorte espacial de 9.356.933m2, que representa $46 \%$ da área total da Região de Trindade 2, localizada entre o trevo da cidade de Trindade e a linha divisória com o Município de Goiânia e compõem a Macrozona de Desenvolvimento Econômico do perímetro urbano da cidade de Revista Cerrados, Montes Claros/MG, v. 18, n. 1, p. 189-219, jan./jun.-2020 
PEREIRA, D. B. S.; FERREIRA, W. R.

Reflexos das ocupações urbanas na mobilidade às margens da Rodovia Estadual GO-060 entre Goiânia (GO) e Trindade (GO)

Trindade (GO), de acordo com o Plano Diretor de 2008 (PREFEITURA MUNICIPAL DE GOIÂNIA, 2008).

Figura 11 - Recorte espacial da Região Trindade 2 - Anos 2009 e 2015

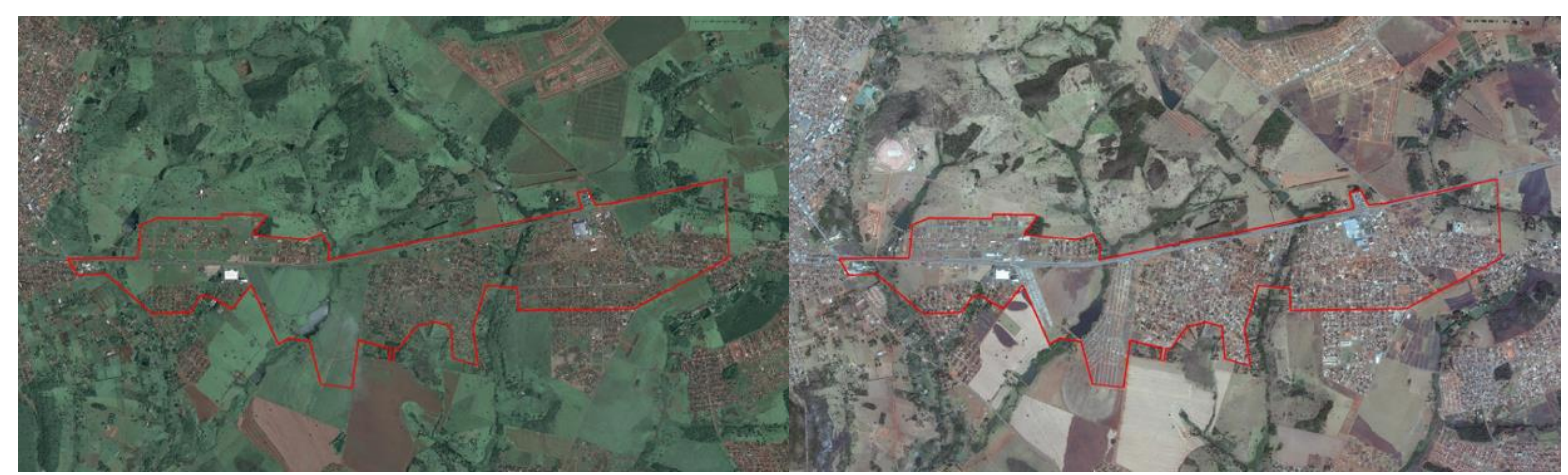

Fonte: Pereira (2017).

Para o cálculo das alterações espaciais ocorridas, primeiramente foram elaborados mapas denominados cheios e vazios, com base em imagens do Google Earth Pro, referentes aos anos de 2009 e 2015, tendo em vista que o Município de Trindade não possui o mapa urbano digital. A partir da elaboração do mapa de cheios e vazios, para cada uma das tipologias em análise, foram calculados os lotes vagos e ocupados nos anos de 2009 e 2015, e foram calculadas as projeções das áreas construídas e suas diferenças no mesmo recorte espacial, conforme descrito na metodologia e que constam no Gráfico 2.

Gráfico 2 - Acréscimo das áreas de ocupação (\%) para as tipologias entre os anos de 2009 e 2015, Região Trindade 2

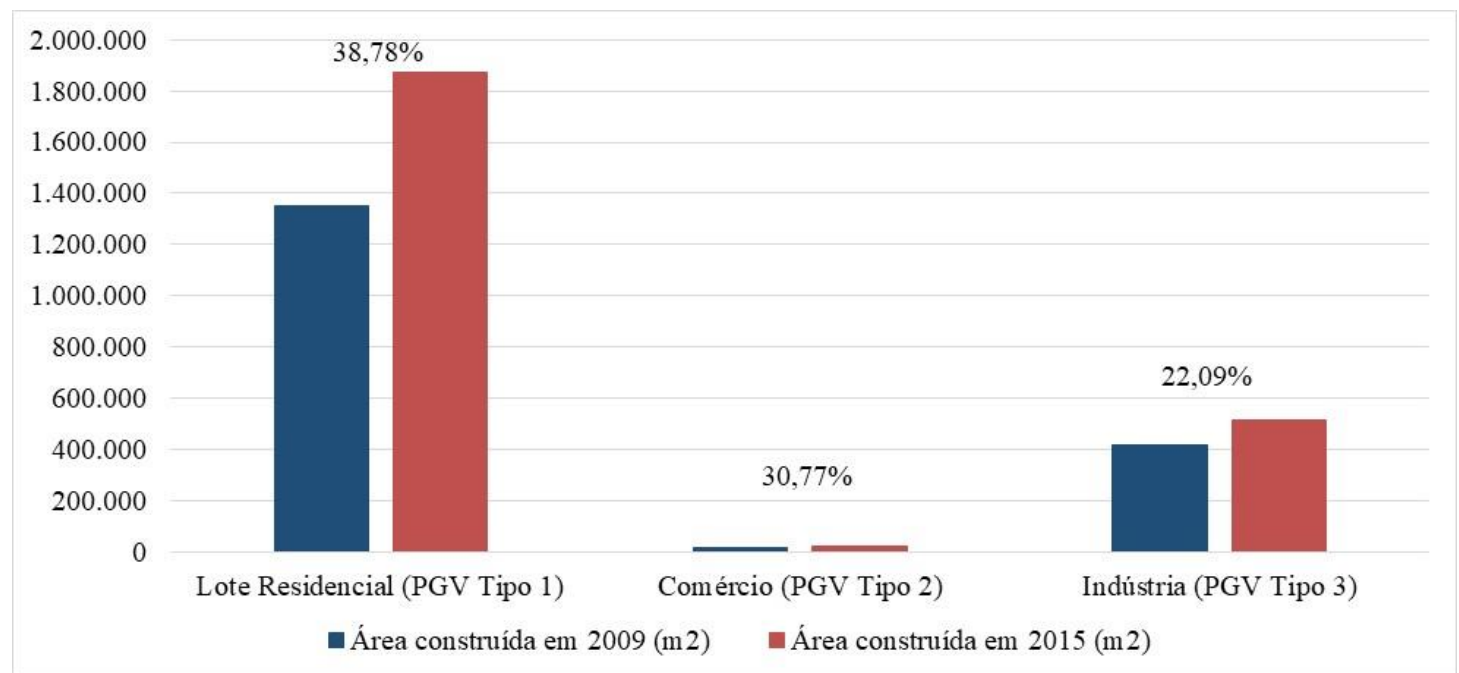

Fonte: Pereira (2017).

Revista Cerrados, Montes Claros/MG, v. 18, n. 1, p. 189-219, jan./jun.-2020 
PEREIRA, D. B. S.; FERREIRA, W. R.

Reflexos das ocupações urbanas na mobilidade às margens da Rodovia Estadual GO-060 entre Goiânia (GO) e Trindade $(\mathrm{GO})$

Percebeu-se, ao analisar o Gráfico 2, que o Lote Residencial - PGV Tipo 1 é predominante na região em relação às ocupações de uso do solo em detrimento do Comércio - PGV Tipo 2 e Indústria - PGV Tipo 3, e apresentaram uma média de crescimento de (+30\%) nas áreas construídas (m2) no período de 06 anos de 2009 a 2015, refletindo a dinâmica das ocupações na região metropolitana de Goiânia, no entorno da Rodovia GO-060, entre as cidades de Goiânia e Trindade.

A partir dos resultados encontrados para as áreas construídas das tipologias PGVs das Regiões Oeste/Mendanha e Região Trindade 2, com a predominância de Lote Residencial e Comércio, pode-se verificar uma certa influência com as variações do fluxo veicular dos diversos modos de transporte, nas áreas do entorno da rodovia e os bairros adjacentes.

\section{Etapa (ii) - Análise do Fluxo Veicular}

Consistiu em avaliar o impacto do acréscimo de área construída das tipologias das referidas regiões no fluxo de viagens veiculares, utilizando-se os dados da AGETOP (2017) para a elaboração dos Gráficos 3,4,5 e 6 . O intenso fluxo misto de viagens, compreendendo os diversos modos de transporte: carro/moto, caminhão leve/micro-ônibus, caminhão/ônibus, bitrem/rodotrem, tem sido marcante e preponderante nessas regiões, constituindo-se em uma formação de rede urbana e regional, acarretando uma variação anual do quantitativo total de viagens do fluxo misto na Rodovia GO-060, dos anos de 2013 a 2016.

Os dados de fluxo de veículos se caracterizam, a partir de 2013, pela inexistência de registro de dados anteriores, e foram medidos e coletados de forma ininterrupta, em pontos estratégicos de monitoramento eletrônico, mediante contagem mecânica por sensores piezoeléctricos instalados no pavimento da rodovia e localizados nas margens direita e esquerda, constituindo-se em pontos de contagem $(\mathrm{Km})$ e contribuindo para a análise dos reflexos do processo de urbanização com a demanda do fluxo veicular.

Nesse contexto, os Gráficos 3,4,5 e 6, mostram as variações das linhas azul e vermelha indicando os lados direito e esquerdo da pista, respectivamente, com os quantitativos do número de viagens em cada ponto de contagem $(\mathrm{Km})$, ressaltando os picos do fluxo de veículos em função das interferências do uso do solo, contabilizando em cada 
PEREIRA, D. B. S.; FERREIRA, W. R.

Reflexos das ocupações urbanas na mobilidade às margens da Rodovia Estadual GO-060 entre Goiânia (GO) e Trindade (GO)

ponto o número total anual de veículos dos diversos modos de transporte, que trafegam ao longo do trecho rodoviário da GO-060.

Gráfico 3 - Quantitativo do Número de Viagens por Ponto de Contagem - Ano 2013

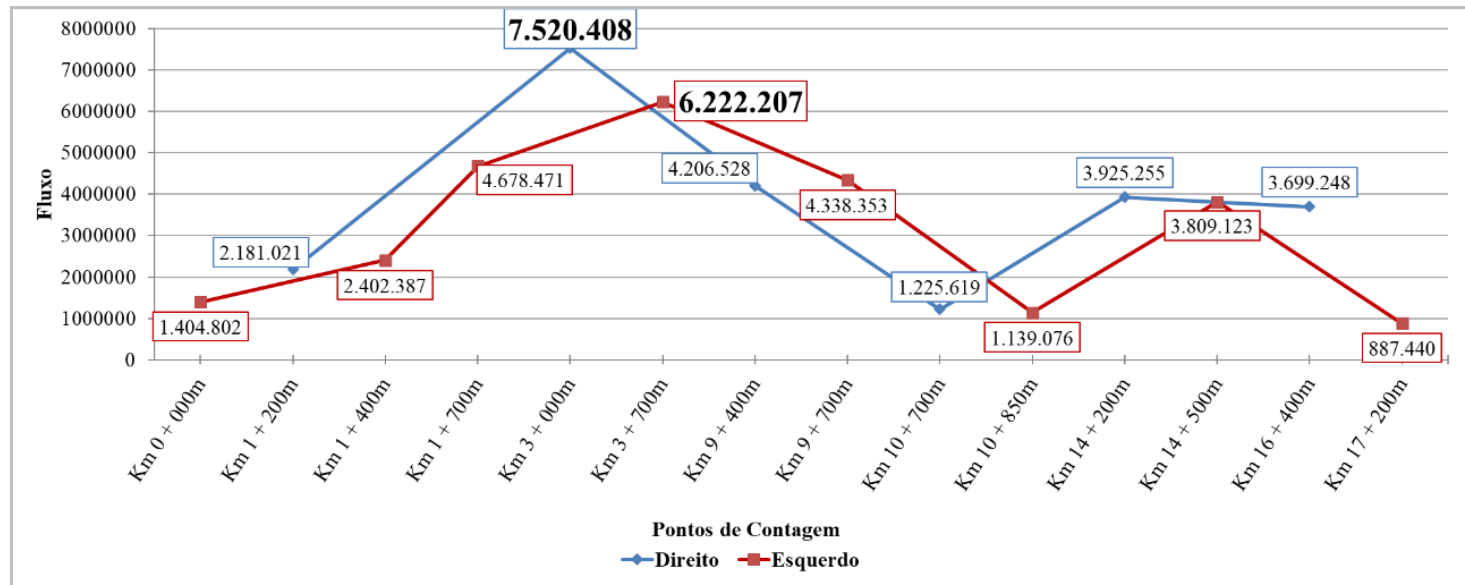

Fonte: Pereira (2017).

Os dados quantitativos do número de viagens do Gráfico 3 mostraram as variações do fluxo de veículos dos modos de transporte em todos os pontos de contagem, relativos ao ano de 2013. Pode-se observar, portanto, que os picos de fluxos de veículos incidiram, respectivamente, no $\mathrm{Km} 3+000 \mathrm{~m}$ do lado direito e no $\mathrm{Km} 3+700 \mathrm{~m}$ do lado esquerdo da pista.

Gráfico 4 - Quantitativo do Número de Viagens por Ponto de Contagem - Ano 2014

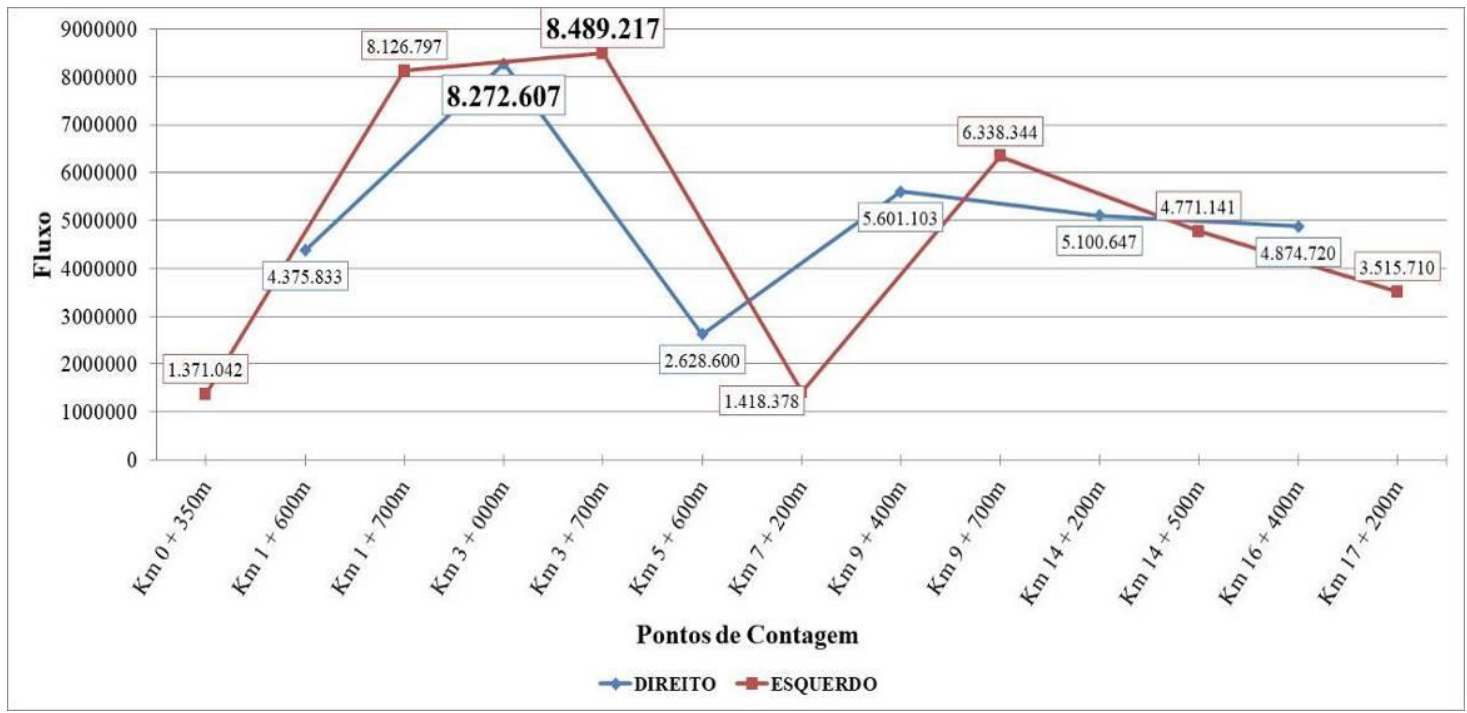

Fonte: Pereira (2017).

Revista Cerrados, Montes Claros/MG, v. 18, n. 1, p. 189-219, jan./jun.-2020 
PEREIRA, D. B. S.; FERREIRA, W. R.

Reflexos das ocupações urbanas na mobilidade às margens da Rodovia Estadual GO-060 entre Goiânia (GO) e Trindade (GO)

Os dados quantitativos do número de viagens do Gráfico 4 mostraram as variações do fluxo de veículos dos modos de transporte em todos os pontos de contagem, relativos ao ano de 2014, e observou-se que os picos de fluxos de veículos incidiram também, respectivamente, nos mesmos locais, isto é, no $\mathrm{Km} 3+000 \mathrm{~m}$ do lado direito e no $\mathrm{Km} 3+$ $700 \mathrm{~m}$ do lado esquerdo da pista. Por meio da análise veicular, observou-se a coincidência dos mesmos pontos de pico do fluxo do ano de 2013. Entretanto, houve um acréscimo no fluxo de veículos respectivamente de $(+10 \%)$ e $(+36 \%)$, ensejando um acréscimo parcial nas áreas construídas dos PGVs.

Gráfico 5 - Quantitativo do Número de Viagens por Ponto de Contagem - Ano 2015

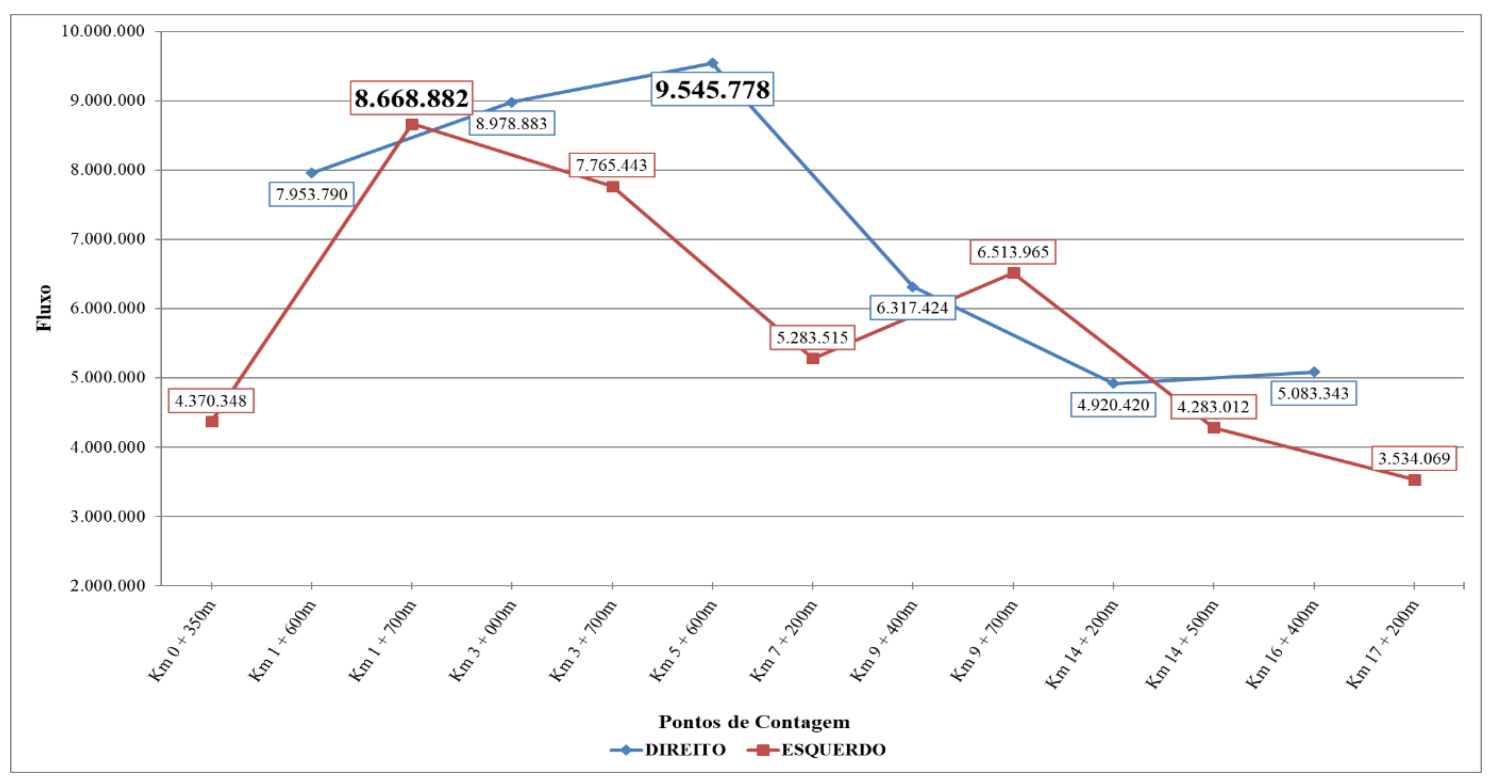

Fonte: Pereira (2017).

Os dados quantitativos do número de viagens do Gráfico 5 mostraram as variações do fluxo de veículos dos modos de transporte em todos os pontos de contagem, relativos ao ano de 2015, e ilustram que os picos de fluxos de veículos incidiram, respectivamente, nos $\mathrm{Km} 5+600 \mathrm{~m}$ do lado direito e no $\mathrm{Km} 1+700 \mathrm{~m}$ do lado esquerdo da pista. Mediante a análise veicular realizada, foram observadas alterações dos pontos de pico do fluxo relativo aos anos de 2013 e 2014.

Entretanto, ainda que constatadas essas alterações nos pontos de picos de fluxos, os pontos dos $\mathrm{Km} 3$ + 000m e Km 3 + 700m continuaram com acréscimo no fluxo de veículos na ordem $(+20 \%)$ e $(+24,8 \%)$ relativo ao ano de 2013 , respectivamente, mostrando a 
PEREIRA, D. B. S.; FERREIRA, W. R.

Reflexos das ocupações urbanas na mobilidade às margens da Rodovia Estadual GO-060 entre Goiânia (GO) e Trindade (GO)

intensidade do transporte motorizado impulsionado pelos PGVs instalados nas proximidades desses pontos e pela dinâmica da ocupação espacial.

Gráfico 6 - Quantitativo do Número de Viagens por Ponto de Contagem - Ano 2016

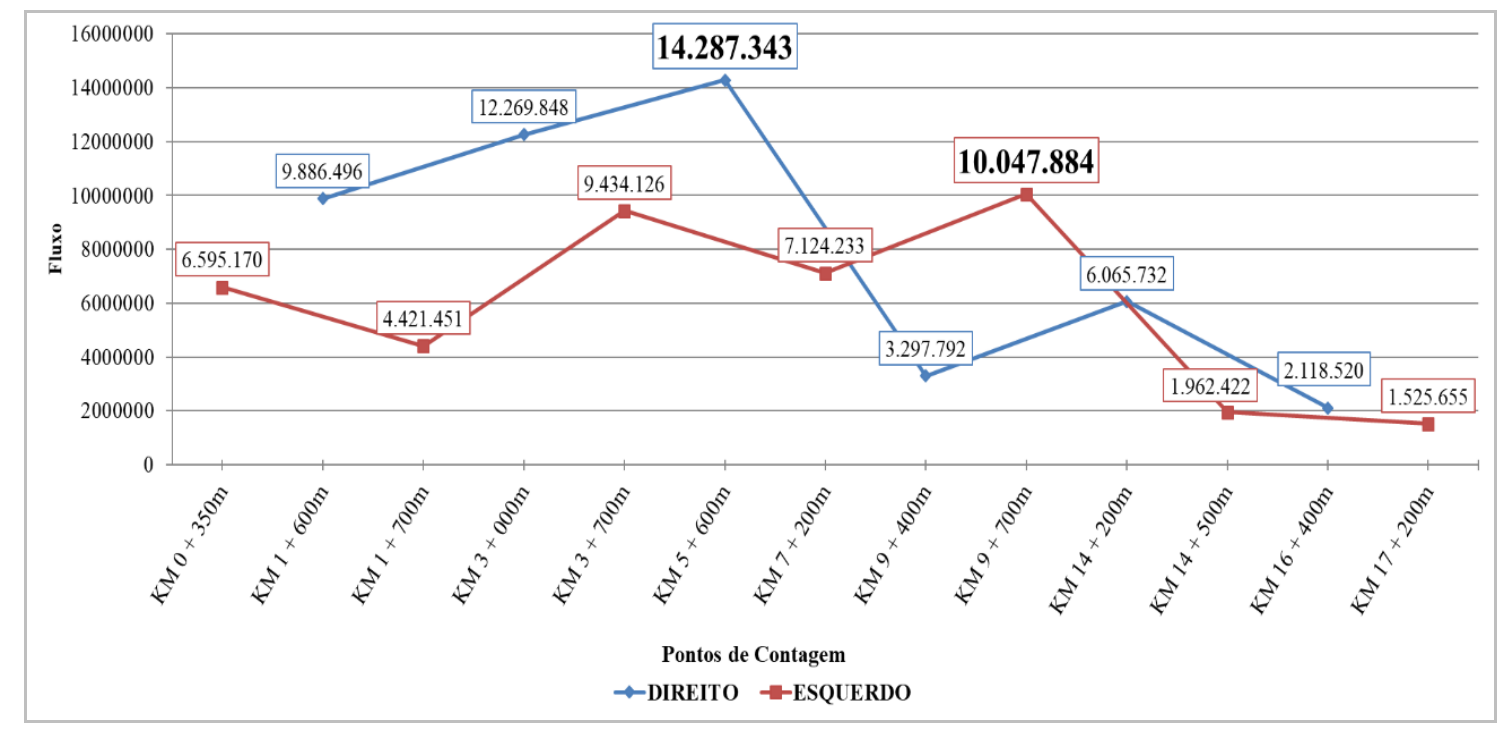

Fonte: Pereira (2017).

Os dados quantitativos do número de viagens do Gráfico 6 mostraram as variações do fluxo de veículos dos modos de transporte em todos os pontos de contagem, relativos ao ano de 2016, e ilustrou-se que os picos de fluxos de veículos incidiram, respectivamente, nos $\mathrm{Km} 5+600 \mathrm{~m}$ do lado direito e no $\mathrm{Km} 9+700 \mathrm{~m}$ do lado esquerdo da pista. Por meio da análise veicular, observou-se que houve alteração apenas no ponto de pico do fluxo no $\mathrm{Km} 9+700 \mathrm{~m}$ relativo ao ano de 2015, com um aumento de (+54,3\%). O ponto de contagem Km $5+600$ m, no ano de 2016 , contou com um acréscimo no fluxo de $(+49,6 \%)$ comparando-se com o ano de 2015.

Entretanto, ao se analisar os fluxos anualmente, constatou-se que nos pontos $\mathrm{Km} 3$ + 000m e Km 3 + 700m, apesar de não serem picos de fluxos no ano de 2016, ainda continuaram crescendo na ordem $(+63,1 \%)$ e $(+51,6 \%)$ relativos ao ano de 2013, respectivamente, mostrando a tendência da intensidade do transporte motorizado nessas regiões, a influência das taxas médias de áreas de ocupação de uso do solo e a proximidade das cidades de Goiânia e Trindade como variáveis impactantes nessa análise do fluxo veicular.

Para entender os picos de demanda de fluxos nestes pontos críticos, foram visualizadas, por meio do Google Earth Pro, as ocorrências de PGVs para os anos de 2013 e 
PEREIRA, D. B. S.; FERREIRA, W. R.

Reflexos das ocupações urbanas na mobilidade às margens da Rodovia Estadual GO-060 entre Goiânia (GO) e Trindade $(\mathrm{GO})$

2016, no sentido de se verificar as alterações espaciais que mais impactaram no fluxo de tráfego da rodovia por diversos modos de transportes em função da dinâmica espacial.

O intenso fluxo misto de viagens, compreendendo os diversos modos de transporte, tem sido marcante e preponderante nessas regiões inseridas entre as cidades de Goiânia e Trindade, interligadas por uma extensão de $18 \mathrm{Km}$. Essas cidades sofrem um processo de metropolização, cujas relações espaciais efetivam a inserção dessas regiões em áreas conurbadas, com a circulação de pessoas, mercadorias e informações, constituindo-se em uma formação de rede urbana e regional, acarretando uma variação anual do quantitativo total de viagens do fluxo misto na Rodovia GO-060, como se observa no Gráfico 7, entre as cidades de Goiânia e Trindade, dos anos de 2013 a 2016.

Gráfico 7 - Viagens (Fluxo Misto): Série Histórica - Anos 2013 a 2016

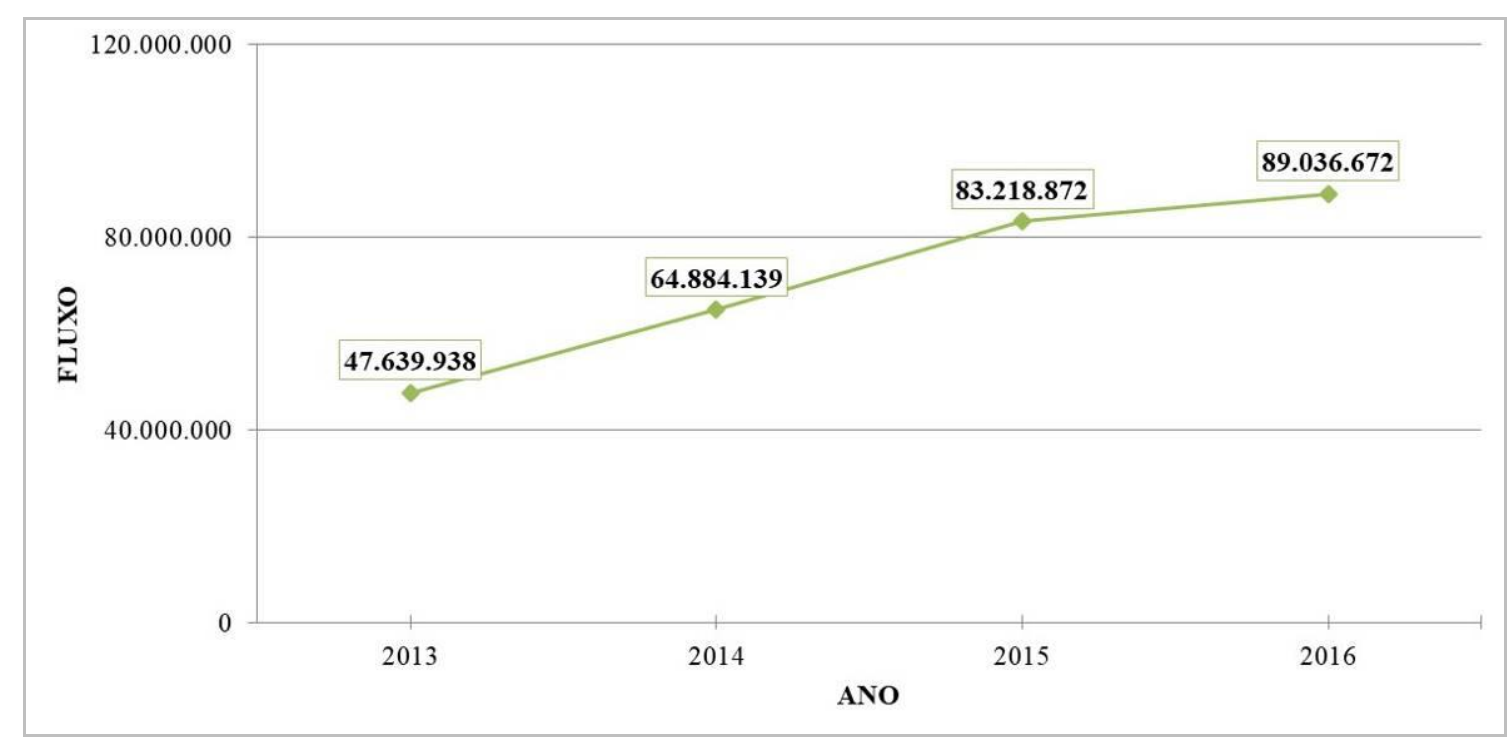

Fonte: Pereira e Ferreira (2018).

Observou-se que os dados quantitativos e percentuais do total de viagens do fluxo veicular do Gráfico 7 apresentaram um crescimento de (+ 87\%) do ano de 2013 a 2016, refletindo a intensidade do fluxo veicular comparado com as taxas médias de ocupações espaciais das Regiões Oeste/Mendanha $(+15 \%)$ e Trindade $2(+30 \%)$. Essa variação no crescimento do fluxo veicular pode estar relacionada com as densidades demográficas, renda da população, pela implantação de polos atrativos e geradores de viagens no entorno da rodovia e também pela influência do mercado consumidor das cidades de Goiânia e Trindade. 
PEREIRA, D. B. S.; FERREIRA, W. R.

Reflexos das ocupações urbanas na mobilidade às margens da Rodovia Estadual GO-060 entre Goiânia (GO) e Trindade (GO)

\section{Etapa (iii) - Análise da Mobilidade}

Consistiu no levantamento de dados quantitativos das populações das regiões em estudo, segundo as estimativas de crescimento populacional a partir do Censo Demográfico 2000, Contagem Populacional 2007 e Censo Demográfico 2010 do IBGE (2017), para compreender e analisar a influência da população no contexto da mobilidade urbana das regiões em estudo. Para calcular o índice de mobilidade total, utilizou-se a metodologia proposta por Cardoso (2005), considerando para o cálculo a somatória dos totais de viagens do fluxo veicular de todos os modos de transporte com as do transporte público e, a partir disso, dividiu-se o resultado do total geral pela somatória das populações das Regiões Oeste/Mendanha e de Trindade 2, como pode ser visualizado no Gráfico 8.

Gráfico 8 - Índice de Mobilidade Total das Regiões Oeste/Mendanha e Trindade 2 - Anos 2013 a 2016

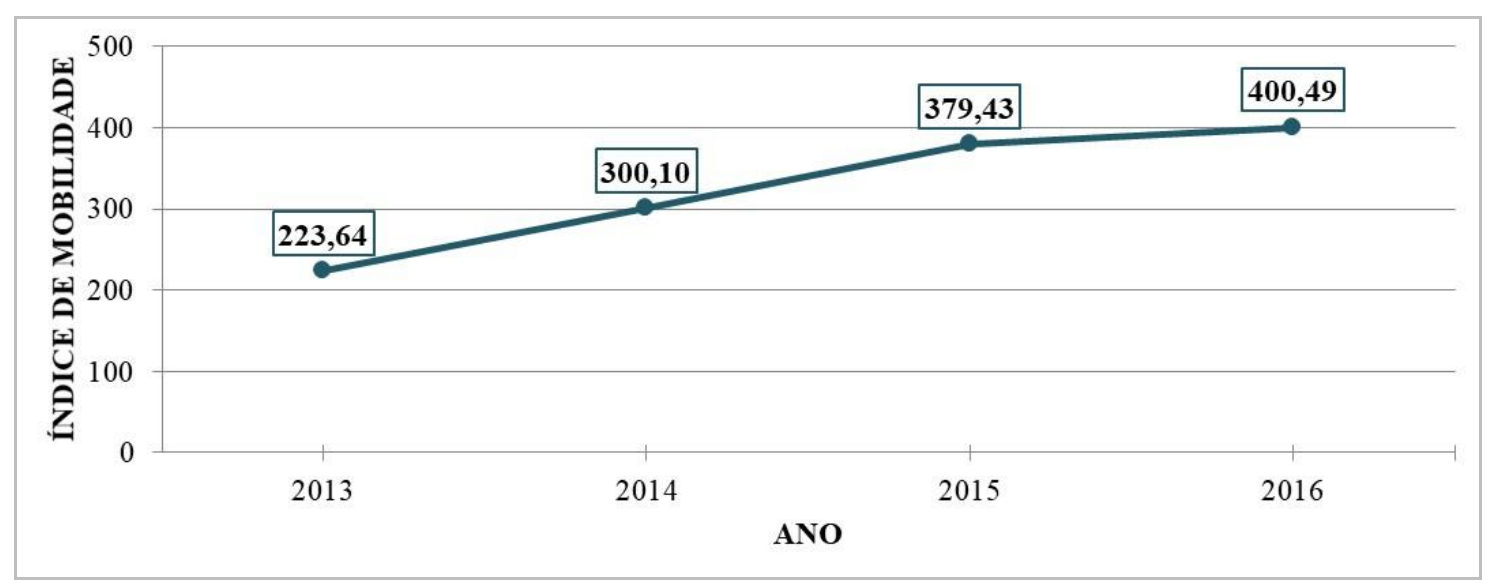

Fonte: Pereira e Ferreira (2018).

No Gráfico 8, constatou-se que a variação do índice de mobilidade foi de $(+79 \%)$ para o período de 2013 a 2016, utilizando-se o quantitativo total do número de viagens e dados populacionais do Censo Demográfico 2010 do IBGE (2017), mostrando a intensidade do grau de mobilidade e fluidez da rodovia nessas regiões. Para avaliar a correlação estatística entre as matrizes $1^{\mathrm{a}}$ e $2^{\mathrm{a}}$, sendo a $1^{\mathrm{a}}$ o total de viagens do fluxo misto veicular e do transporte público e a $2^{\mathrm{a}}$ representando a população total das regiões em estudo, o resultado do coeficiente foi de (+98\%) apresentando uma correlação estatística muito forte, isto é, comprovando-se devido à proximidade do valor de $100 \%$. 
PEREIRA, D. B. S.; FERREIRA, W. R.

Reflexos das ocupações urbanas na mobilidade às margens da Rodovia Estadual GO-060 entre Goiânia (GO) e Trindade (GO)

\section{CONSIDERAÇÕES FINAIS}

Observou-se, que o grau de urbanização no período em análise destacou-se nas tipologias de ocupação PGVs Tipo Comércio/Indústria (25,74\%) e (30,77\%) e Tipo Residencial (11,41\%) e (38,78\%) para as Regiões Oeste/Mendanha e Trindade 2, respectivamente. Isso mostra a tendência de ocupação do uso do solo e seus reflexos no fluxo veicular no entorno da Rodovia GO-060, que tem a função de eixo estruturante na formação socioespacial e de redes na região metropolitana em estudo.

$\mathrm{O}$ aumento e a variação significativa nos quantitativos do número de viagens por ponto de contagem dos equipamentos eletrônicos instalados ao longo da rodovia, relativos aos anos de 2013 a 2016, mostraram as alterações dos picos de contagem dos fluxos veiculares, a intensidade do transporte motorizado, a influência das taxas médias de ocupação das tipologias e a proximidade das cidades de Goiânia e Trindade como variáveis impactantes nessa análise do fluxo veicular por diversos modos de transporte.

Os dados revelaram o crescimento de $(+87 \%)$ no total de viagens do fluxo de veículos do ano de 2013 a 2016, refletindo a intensidade de motorização, comparado com as taxas médias de ocupações espaciais das Regiões Oeste/Mendanha $(+15 \%)$ e Trindade 2 (+30\%), tornando-se um desafio para a gestão de políticas públicas de mobilidade urbana.

Por meio da função (Correl) do Microsoft Excel, o resultado de (+98\%) mostrou o quanto estas duas variáveis estão vinculadas e relacionadas, constatando-se, assim, que quanto maior a população das regiões, maior a probabilidade de se aumentar o número de viagens e, com isso, influenciar o grau de mobilidade em uma escala dinâmica de ascensão.

Ao final, torna-se evidente que as transformações nas ocupações do uso do solo por loteamentos, comércios e indústrias caracterizados com PGVs nas margens da rodovia, trazem impactos na intensidade, no volume do quantitativo do número de viagens em pontos de contagem $(\mathrm{Km})$ e do fluxo total veicular por diversos modos de transportes, gerando reflexos na mobilidade urbana. Este cenário se modifica, à medida que novos PGVs se instalam nas áreas do entorno da rodovia, promovendo reflexos na mobilidade urbana. 
PEREIRA, D. B. S.; FERREIRA, W. R.

Reflexos das ocupações urbanas na mobilidade às margens da Rodovia Estadual GO-060 entre Goiânia (GO) e Trindade (GO)

\section{REFERÊNCIAS}

AGETOP - Agência Goiana de Transportes e Obras Públicas. Núcleo de Segurança Rodoviária. Dados estatísticos de fluxo veicular. Goiânia, 2017.

AKISHINO, Pedro. Estudos de Tráfego. Apostila do Curso de Graduação em Engenharia Civil. Departamento de Transportes da Universidade Federal do Paraná (UFPR), v. 1, 2004

BRASIL. Ministério das Cidades. Mobilidade e Desenvolvimento Urbano. In: Gestão integrada da mobilidade urbana. Brasília: DF, 2006.

CARDOSO, C. E. de P. Evolução da Mobilidade no Município de São Paulo - $15^{\circ}$ Congresso Brasileiro de Transporte e Trânsito, ANTP, 2005.

CET - Companhia de Engenharia de Tráfego. Noções Básicas de Engenharia de Tráfego. Série Boletim Técnica da CET nº 5. São Paulo, CET, 1977.

CORRÊA, R. L. Espaço: um conceito-chave da geografia. In: CASTRO, I. E.; GOMES, P. C. C.; CORREA, R. L. Geografia: conceitos e temas. $11^{\text {a }}$ ed. Rio de Janeiro: Bertrand Brasil, 2008. p. 15-47.

CORRÊA, R. L. O espaço urbano. $3^{\text {a }}$ ed. São Paulo: Editora Ática, Série Princípios, 1995.

DENATRAN - Departamento Nacional de Trânsito. Frota Nacional. Disponível em < http://www.denatran.gov.br/frota2016.htm>. Acesso em 06 jun 2017.

DENATRAN - Departamento Nacional de Trânsito. Manual de Procedimentos para o Tratamento de Polos Geradores de Tráfego. Brasília: DENATRAN/FGV, 2001.

FERRARA, L. D. Olhar Periférico: informação, linguagem, percepção ambiental. São Paulo: EdUSP, 1999.

FERRARI, C. Dicionário de urbanismo. 1 ed. São Paulo: Editora Disal, 2004.

FERREIRA, W. R. O espaço público nas áreas centrais: a rua como referência - um estudo de caso em Uberlândia-MG. 2002. Tese (Doutorado em Geografia Humana) - Faculdade de Filosofia, Letras e Ciências Humanas, Universidade de São Paulo, São Paulo, 2002.

Disponível em: < http://www.teses.usp.br/teses/disponiveis/8/8136/tde-28042006-103725/ptbr.php. Acesso em 15 jan. 2018.

GOIÁS. Lei complementar n ${ }^{\circ}$ 27, de 30 de dezembro de 1999. Cria a Região Metropolitana de Goiânia, autoriza o Poder Executivo a instituir o Conselho de Desenvolvimento da Região Metropolitana de Goiânia, a Secretaria Executiva e a constituir o Fundo de Desenvolvimento Metropolitano de Goiânia e dá outras providências correlatas. Goiás, 1999. Disponível em: 
PEREIRA, D. B. S.; FERREIRA, W. R.

Reflexos das ocupações urbanas na mobilidade às margens da Rodovia Estadual GO-060 entre Goiânia (GO) e Trindade (GO)

<http://www.gabinetecivil.goias.gov.br/leis_complementares/1999/lei_complementar_n27.ht m>. Acesso em: 15 ago. 2017.

GOMES, P. C. C. O conceito de região e sua discussão. In: CASTRO, I. E.; GOMES, P. C. C.; CORREAA, R. L. Geografia: conceitos e temas. $11^{a}$ ed. Rio de Janeiro: Bertrand Brasil, 2008.

HISSA, C. E. V. A mobilidade das fronteiras: inserções da geografia na crise da modernidade. $1^{\text {a }}$ reimpressão. Belo Horizonte: UFMG, 2006.

IBGE - Instituto Brasileiro de Geografia e Estatística. Brasil em Síntese. Cidades @, 2017. Disponível em: <http://www.cidades.ibge.gov.br>. Acesso em 15 jun. 2017.

IBGE - Instituto Brasileiro de Geografia e Estatística. Censo demográfico 2010.

Características da População e dos Domicílios - Resultados do Universo. Rio de Janeiro, (2011). Disponível em: <http://www.ibge.gov.br/english/estatistica/populacao/censo2010/ caracteristicas_da_populacao/resultados_do_universo.pdf >. Acesso em 16 fev. 2015.

IBGE - Instituto Brasileiro de Geografia e Estatística. Sinopse do Censo Demográfico 2010. Disponível em: <http://www.censo2010.ibge.gov.br/sinopse/index.php?uf=52\&dados=0>. Acesso em 16 abr 2017.

KNEIB, E. C. Mobilidade Urbana e Qualidade de Vida: Do Panorama Geral ao Caso de Goiânia. Revista UFG/Universidade Federal de Goiás. Ano XIV nº 12 - julho de 2012, p.71.

KNEIB, E. C. Subcentros urbanos: contribuição conceitual e metodológica à sua definição e identificação para planejamento de transportes. 2008. 207 f. Tese (Doutorado em Transportes), Departamento de Engenharia Civil e Ambiental, Universidade de Brasília, Brasília, DF, 2008.

KNEIB, E. C. Caracterização de Empreendimentos Geradores de Viagens: Contribuição Conceitual à Análise de seus Impactos no Uso, Ocupação e Valorização do Solo Urbano. 2004. 168 f. Dissertação (Mestrado em Transportes), Departamento de Engenharia Civil e Ambiental, Universidade de Brasília, Brasília, DF, 2004.

MARICATO, E. As idéias fora do lugar e o lugar fora das idéias: planejamento urbano no Brasil. In: ARANTES, O.; VAINER, C.; MARICATO, E. (Org.). A cidade do pensamento único: desmanchando consensos. $2^{\mathrm{a}}$ ed. Petrópolis: Vozes, 2000, p. $121-192$.

NETO, A.T. Reflexões acerca de região. Publicado no Observatório Geográfico de Goiás, 2002. Disponível em:

<https://observatoriogeogoias.iesa.ufg.br/up/215/o/teixeira_neto_ant_nio_reflex_es_regi_o.pd f>. Acesso em 12 jan 2017. 
PEREIRA, D. B. S.; FERREIRA, W. R.

Reflexos das ocupações urbanas na mobilidade às margens da Rodovia Estadual GO-060 entre Goiânia (GO) e Trindade (GO)

PEREIRA, D. B. de S. Intervenções espaciais e mobilidade urbana de rodovias em regiões metropolitanas. 2019. $271 \mathrm{f}$. Tese (Doutorado em Geografia), Instituto de Geografia, Universidade Federal de Uberlândia, Uberlândia, 2019.

PEREIRA, D. B. de S.; FERREIRA, W. R. (2018). Influência do uso e ocupação do solo no sistema de transportes e mobilidade no contexto de rodovia em região metropolitana: estudo de caso em Goiânia (GO), Brasil. Atas do $8^{\circ}$ Congresso Luso-Brasileiro para o Planeamento Urbano, Regional, Integrado e Sustentável: PLURIS 2018. Coimbra, Portugal, 24 a 26 de outubro de 2018. pp. 1027-1052.

PONS, J. M. S.; REYNÉS, M. R. M. Geografía de los transportes. Palma (Illes Balears): Universitat de lês Illes Balears, 2004.

PORTUGAl, L. da S. Polos geradores de viagens orientadas à qualidade de vida e ambiental: modelos e taxas de geração de viagens. Rio de Janeiro: Interciência, 2012.

PORTUGAL, L. S.; GOLDNER, L. G. Estudo de Polos Geradores de Tráfego e de seus impactos nos sistemas viários e de transportes. 1. ed. São Paulo: Edgard Blucher, 2003.

PREFEITURA MUNICIPAL DE GOIÂNIA. Lei n ${ }^{\circ} 171$ de 29 de maio de 2007. Plano Diretor de Goiânia 2007. Dispõe sobre o Plano Diretor e o processo de planejamento urbano do Município de Goiânia e dá outras providências. Prefeitura Municipal de Goiânia, atualizado 2009.

PREFEITURA MUNICIPAL DE TRINDADE. Plano Diretor de Trindade 2008. Lei Complementar $n^{\circ}$ 008, 02 de Junho de 2008. Secretaria de Planejamento Municipal, 2008.

RAFFESTIN, C. Por uma Geografia do Poder. São Paulo: Ática, 1993.

SANTOS, M. Por uma Geografia Nova: da crítica da Geografia a uma Geografia Crítica. 6. ed. São Paulo: Editora da Universidade de São Paulo, 2004. - (Coleção Milton Santos;2).

SANTOS, M. Espaço e Método. São Paulo. Nobel, 3. Edição, 1992.

SECIMA - Secretaria de Estado de Meio Ambiente, Recursos Hídricos, Infraestrutura, Cidades e Assuntos Metropolitanos. Análise da mobilidade urbana e metropolitana. Região Metropolitana de Goiânia. Plano de desenvolvimento integrado. Universidade Federal de Goiás, UFG. Goiânia, 2017. Disponível em: < http://pdi-

rmg.desenvolvimento.go.gov.br/wp-content/uploads/2017/10/7-Análise-da-MobilidadeUrbana-e-Metropolitana.pdf >. Acesso em 17 mar. 2018.

SOARES, B. R.; ARAÚJO, F. A. V. Relação cidade-campo: desafios e perspectivas. CAMPO-TERRITÓRIO: revista de geografia agrária, v.4, n. 7, p. 201-229, fev. 2009. Disponível em < file:///C:/Users/Denis\%20Biolkino/Downloads/11894-44040-1-PB.pdf>. Acesso em 19 dez. 2017. 
PEREIRA, D. B. S.; FERREIRA, W. R.

Reflexos das ocupações urbanas na mobilidade às margens da Rodovia Estadual GO-060 entre Goiânia (GO) e Trindade (GO)

SPOSITO, M. E. B. Segregação socioespacial e centralidade urbana. In: VASCONCELOS, P. de A.; CORRÊA, R. L.; PINTAUDI, S. M. A Cidade Contemporânea: segregação espacial. 1. ed., $1^{\mathrm{a}}$ reimpressão. - São Paulo: Contexto, 2016.

SPOSITO, M. E. B. Capitalismo e urbanização. 6. ed. - São Paulo: Contexto, 1994. VASCONCELLOS, E. A. Políticas de transporte no Brasil: a construção da mobilidade excludente. Barueri, SP: Manole, 2013.

VASCONCELLOS, E. A. Transporte urbano, espaço e equidade: análise das políticas públicas. São Paulo: Annablume, 2001.

VASCONCELLOS, E. A. Transporte urbano nos países em desenvolvimento: reflexões e propostas. São Paulo: Editoras Unidas, 1996.

VESENTINI, J. W. Sociedade e espaço: geografia geral e do Brasil. $44^{\mathrm{a}}$ ed. atual. e reform. São Paulo: Ática, 2005.

Autores

Denis Biolkino de Sousa Pereira - Possui Graduação em Engenharia Civil pela Universidade Federal de Goiás (UFG), Graduação em Direito pela Pontifícia Universidade Católica de Goiás (PUC/GO), Mestrado em Transportes pela Universidade de Brasília (UnB) e Doutorado em Geografia pela Universidade Federal de Uberlândia (UFU) através do DINTER IFG/UFU (2015). Atualmente é Professor titular no ensino básico, técnico, tecnólogo e superior do Instituto Federal de Educação, Ciência e Tecnologia de Goiás (IFG).

William Rodrigues Ferreira - Possui graduação em Geografia pela Universidade Federal de Uberlândia (UFU), Mestrado em Transportes pela Universidade de Brasília (UnB) e Doutorado em Geografia Humana pela Universidade de São Paulo (USP). Atualmente é Professor do Programa de Pós-Graduação em Geografia e do Programa de Pós-Graduação em Saúde Ambiental e Saúde do Trabalhador da Universidade Federal de Uberlândia (UFU).

Artigo recebido em: 07 de fevereiro de 2020.

Artigo aceito em: 10 de maio de 2020.

Artigo publicado em: 19 de maio de 2020. 